NBER WORKING PAPER SERIES

\title{
DECENTRALIZATION AND EFFICIENCY OF SUBSIDY TARGETING: EVIDENCE FROM CHIEFS IN RURAL MALAWI
}

\author{
Pia M. Basurto \\ Pascaline Dupas \\ Jonathan Robinson \\ Working Paper 23383 \\ http://www.nber.org/papers/w23383 \\ NATIONAL BUREAU OF ECONOMIC RESEARCH \\ 1050 Massachusetts Avenue \\ Cambridge, MA 02138 \\ May 2017
}

This research makes use of data collected as part of a research grant funded by the Bill and Melinda Gates foundation, whose support is gratefully acknowledged. The data collection protocols were approved by the IRBs of Stanford, UCLA, and UCSC. We thank Aaron DibnerDunlap, Rachel Levenson and Michael Roscitt for outstanding field research assistance, and Travis Baseler and Santiago Saavedra for excellent research assistance. We are grateful to IPA and IPA Malawi for administrative assistance. We thank Siwan Anderson, Eric Edmonds, Marcel Fafchamps, Patrick Francois, Mushfiq Mobarak, Ben Olken, Quentin Stoeffler and numerous seminar participants for helpful comments. All errors are our own. The views expressed herein are those of the authors and do not necessarily reflect the views of the National Bureau of Economic Research.

NBER working papers are circulated for discussion and comment purposes. They have not been peer-reviewed or been subject to the review by the NBER Board of Directors that accompanies official NBER publications.

(C) 2017 by Pia M. Basurto, Pascaline Dupas, and Jonathan Robinson. All rights reserved. Short sections of text, not to exceed two paragraphs, may be quoted without explicit permission provided that full credit, including $(\odot)$ notice, is given to the source. 
Decentralization and Efficiency of Subsidy Targeting: Evidence from Chiefs in Rural Malawi Pia M. Basurto, Pascaline Dupas, and Jonathan Robinson

NBER Working Paper No. 23383

May 2017

JEL No. D73,I38,O12,Q12

\begin{abstract}
Developing countries spend vast sums on subsidies. Beneficiaries are typically selected via either a proxy-means test (PMT) or through a decentralized identification process led by local leaders. A decentralized allocation may offer informational or accountability advantages, but may be prone to elite capture. We study this tradeoff in the context of two large-scale subsidy programs in Malawi (for agricultural inputs and for food) decentralized to traditional leaders ("chiefs") who are asked to target the needy. Using high-frequency household panel data on neediness and shocks, we find that nepotism exists but has only limited mistargeting consequences. Importantly, we find that chiefs target households with higher returns to farm inputs, generating an allocation that is more productively efficient than what could be achieved through a PMT. This could be welfare improving, since within-village redistribution is common.

Pia M. Basurto

Department of Economics

University of California, Santa Cruz

Santa Cruz, CA 95064

mbasurto@ucsc.edu

Pascaline Dupas

Department of Economics

Stanford University

579 Serra Mall

Stanford, CA 94305-6072

and CEPR

and also NBER

pdupas@stanford.edu

Jonathan Robinson

Department of Economics

University of California, Santa Cruz

457 Engineering 2

Santa Cruz, CA 95064

and NBER

jmrtwo@ucsc.edu
\end{abstract}




\section{Introduction}

Targeting programs such as subsidies to needy households is an important part of what governments do. To do this effectively, governments must first identify who is truly needy, which may be difficult in developing countries where government infrastructure and information technology is limited (particularly in rural areas). Governments typically have the choice to administer such selection of eligibles centrally, or to decentralize authority to local communities (usually these programs are officially administered by local leaders) 11 Decentralization has two main benefits: (1) local leaders are almost surely more informed about the relative neediness of people in their village than a centralized bureaucracy, especially in a context in which most people do not file a tax return; and (2) local leaders will be more accountable to villagers, particularly if leaders face village electoral pressure or are motivated by reputation concerns. On the downside, decentralization may open the door for corruption or nepotism.

This paper uses rich panel data collected from a sample of 1,559 households over four survey rounds in 2011-2013 to explore this fundamental trade-off in the context of two subsidy programs in Malawi - the well-known farming input subsidy program which provides subsidies for fertilizer and hybrid seeds once a year, and a one-time food aid relief program put in place after a drought in 2012. These programs were conceived as anti-poverty programs and the selection of beneficiaries was decentralized to local traditional leaders, called chiefs. How well do chiefs target the program?

This is a setting in which the tradeoff between nepotism and information is particular salient. On the one hand, nepotism is possible since chiefs cannot be held accountable via electoral pressure (in contrast to papers such as Bardhan and Mookherjee 2000, 2005; Bardhan 2002) - the position of chief in Malawi is hereditary and chiefs face fairly weak oversight. There is also no strict eligibility rule provided by the government (only general guidance on who should be "considered") and no government backchecking of allocations 2 . But on the other hand, local information is critical, along two main dimensions: (1) shocks are common and chiefs likely have good information on recent household-specific economic conditions; and (2) the return to inputs will likely be heterogenous across households within a village and related to factors such as soil type, access to credit, household composition, etc. Since there is some non-negligible level of income pooling, targeting the inputs where they will increase output the most (rather than to the neediest) may be welfare improving: the input subsidy can be allocated based on productive efficiency to increase the size of the pie, and ex post inter-household transfers can be used to reduce poverty.

\footnotetext{
${ }^{1}$ See Coady et al. (2004) for a detailed discussion of various forms of targeting.

${ }^{2}$ See Niehaus et al. (2013) for a discussion of optimal targeting rules when programs are implemented via local, possibly corruptible, agents, but in which agents can be punished if they do not follow the rule.
} 
In this paper, we compare the allocation chosen by chiefs to that which would have obtained under an alternative of a proxy-means test (PMT) based on a household survey. We are interested in two sets of questions. First, how common are errors of exclusion (truly needy households not getting the subsidy) under the chiefs, and is this error rate higher or lower than what would have occurred under the PMT? Do chiefs use local information to target households which have suffered recent negative shocks? Do they favor relatives? Second, do chiefs take into consideration productive efficiency when allocating the input subsidies? Specifically, do they target the agricultural subsidies to households with higher returns to fertilizer?

To answer the first question, we follow Alatas et al. (2011, 2013) and use observed food expenditures in the immediate pre-subsidy period as our measure of neediness. We find evidence that both the chiefs and the PMT miss a substantial fraction of poor people, but that the chiefs miss significantly more: chiefs wrongly exclude about $15 \%$ of people for both the input and food subsidy, whereas the PMT would have excluded only about $10 \%$ for the input subsidy and $14 \%$ for the food subsidy. We also find evidence of nepotism: chiefs are more likely to target food subsidies to relatives. However, this nepotism appears to have minimal aggregate welfare consequences, since chiefs' relatives are similarly poor to other villagers. Ultimately, we find that both the PMT and the observed chiefs' allocation are pro-poor, consistently outperforming a random allocation (especially in terms of mean squared error). While chiefs do worse than the PMT in terms of poverty targeting, we find that chiefs use their informational advantage to the benefit of households hit with negative shocks: people who have experienced droughts, floods, cattle death, or crop disease are significantly more likely to receive subsidies.

The second part of the paper tests whether chiefs target input subsidies to people with higher returns to agricultural inputs. The test is derived from a model of subsidy allocation in which chiefs have preferences over households (each household has a given welfare weight), but also have information about household-specific returns to agricultural inputs. We assume that there is little heterogeneity in productive returns to food, in which case the allocation of the food subsidy is reflective of the welfare weights. To back out the relative importance of productivity considerations in the chief's objective function, we can thus exploit the wedge between the allocations of the food and input subsidies. Taking this to the data, we find that chiefs indeed allocate relatively more inputs to households with higher gains from fertilizer use, while the PMT would not, suggesting productive efficiency gains from a decentralized system.

Our paper makes several contributions to the literature. Starting with the more narrow contribution, our paper highlights a number of pitfalls for studies aiming to assess the effi- 
ciency of poverty targeting in government programs. We show that assessing the true quality of targeting is very data-demanding: assets like land are noisy predictors of consumption - the R-squared for our PMT regression is only 0.32 in Malawi, and we document similar figures for datasets from Kenya and Uganda. This may be one reason we find lower levels of mistargeting and elite capture here than in previous work which used assets as a proxy for need (i.e. Bardhan and Mookherjee 2006 in West Bengal), including several previous studies in Malawi (Dorward et al. 2008, 2013; Kilic et al. 2013). We also bring attention to the difference between poverty targeting and poverty reduction (the ultimate goal of subsidy programs). In communities with informal income pooling, productive efficiency targeting may be the more effective (albeit indirect) way of reducing poverty. Thus looking only at who gets input subsidies rather than how the produced output is allocated may not be sufficient to gauge the poverty impacts.

Our paper ultimately paints a nuanced view of the targeting of chiefs - while chiefs pick favorites and while they miss more poor people than would a (perfectly implemented) PMT, they also target based on recent economic shocks as well as land productivity. Our results thus represent a data point in favor of relatively good targeting, along with Galasso and Ravallion (2005) for the food-for-education program in Bangladesh, Bardhan and Mookherjee (2006) for credit and farming input subsidies in West Bengal, and Alatas et al. (2013) for government benefits in Indonesia.

PMTs and chiefs are not the only mechanisms that can be used to select beneficiaries. Another common mechanism is community-based targeting (CBT, where communities get together to decide on beneficiaries). Two studies that do careful comparisons between PMT and CBT in the context of cash transfer programs tend to give a modest advantage to the PMT: Alatas et al. $(2012,2013)$ in Indonesia, where the relationship between assets and consumption is somewhat stronger than in contexts we consider; and Stoeffler et al. (2016) in Cameroon, where the CBT implementation appear poor. While the results of these two studies suggest community targeting could at best marginally improve on the chiefs' allocation, exploring the impact of community-based targeting in contexts like ours is an interesting area for future research.

More broadly, we contribute to the literature on the role of traditional authorities in African development. While survey evidence from the Afrobarometer suggests that traditional leaders are perceived to regulate important aspects of the local economy in numerous African countries (Logan, 2011; Michalopoulos and Papaioannou, 2013), the question of whether their existence further undermines weak governance, or instead palliates it, is still unsettled. Acemoglu et al. (2014) find that areas of Sierra Leone where competition among potential chieftaincy heirs was low during and after British colonial rule have significantly 
worse development outcomes today, but higher levels of respect for traditional authorities. They hypothesize that this reflects the ability of uncontested traditional ruling families to simultaneously capture resources and civil society organizations. Our evidence from Malawi mitigates this view: in our context, traditional leaders are uncontested and popular, as in Acemoglu et al. (2014), but effective at targeting input subsidies to productive farmers, possibly putting their village on a higher growth path. $3^{3}$

The layout of the paper is as follows. Section 2 presents some background on the Malawian local governance structure and decentralized subsidy programs. Section 3 discusses the

sample and data. Section 4 presents evidence on poverty-based (mis)targeting. Section 5 tests for productive efficiency targeting. Section 6 concludes.

\section{Institutional Background}

\subsection{Local governance in Malawi and the role of chiefs}

Malawi is a presidential democracy with a single federal legislative body (parliament). At the sub-national level, Malawi is divided into 28 districts each administered by a District Assembly. District Assemblies consist of a combination of democratically elected councilors and members of parliament, together with ex-officio, non-voting members. This local government coexists with a traditional chieftaincy hierarchy. There are four ranks within this hierarchy: Paramount Chief, Traditional Authority (TA), Group Village Headman (GVH), and Village Headman (also known as village chief). In our data, TAs have authority over areas smaller than a district. They oversee from 10 to 45 GVHs, and GVHs oversee between 2 and 10 villages. $4^{4}$

\footnotetext{
${ }^{3}$ Outside of Africa, Anderson et al. (2015) also finds evidence of poor governance by elites in Maharashtra, India. Though democracy appears to be vibrant, there exists elites an entrenched clientilisic vote-trading system in which elites landholders are able to enact policies which lower rural wages in exchange for insurance. As in Acemogulu et al. (2014), this system is so engrained that people report high levels of satisfaction.

${ }^{4} \mathrm{~A}$ brief history of the coexistence of these two systems of local governance is as follows (this note relies heavily on Lihoma 2012, Eggen 2011 and Cammack et al. 2007). Prior to colonialism, local government structures in Malawi varied across regions and ethnic groups. Most local governments included chiefs, but the role of chiefs varied between centralized systems in which the chief's authority was paramount and more decentralized, participatory systems (Lihoma, 2012). Malawi was colonized by Britain in 1891, which attempted a system of direct rule which minimized the authority of chiefs. In 1912, Britain moved towards a system of indirect rule which recognized chiefs as traditional authorities, reporting to the colonial district administrator. In 1933, traditional powers were extended such that chiefs could perform some functions of local government (such as administering communal land and arbitrating disputes in traditional courts), though chiefs were still financially dependent on colonial administrators. Beginning in 1953 and continuing until independence in 1964, the British transferred local authority from chiefs to district councils. While higher-ranked chiefs (TAs) served as ex-officio members of these councils, their powers to act unilaterally were limited (and were officially subordinate to the council itself).
} 
Chiefs in Malawi hold little formal power. They do not have direct control over any public funds and are not allowed to raise local taxes. However, chiefs hold other customary responsibilities. The 1998 Decentralisation Policy and Local Government Act recognized the rights of chiefs to allocate communal land and adjudicate matters related to customary law (in particular customary land). Chiefs also play an advisory and coordination role regarding local development projects: local development funds are in principle spent through groups known as Area Development Committees (headed by TAs) and Village Development Committees (chaired by GVH and composed of ward councilors, MPs, religious leaders, business leaders and youth and women representatives). Finally - and this is the focus of this paper - chiefs are typically relied upon to identify beneficiaries for targeted government programs.

Traditional leadership positions are hereditary. Chiefs who pass away are replaced by someone from the chieftaincy clan. In patrilineal communities, such as in the northern part of the country, chieftancy is inherited from father to son, while in matrilineal communities, like in the southern and central parts of the country where our data comes from, chieftancy is inherited from maternal uncle to nephews (so the first son of the first sister inherits the right to the position) (Chirwa 2014). There are a few female chiefs, but they are often seen as "holding the place for a brother" (Peters 2010).

Chiefs are paid a salary by the government that is known as mswahala, but it is fairly small.5 Chiefs do occasionally charge fees to villagers (in our sample, 44 percent of villagers report having ever made a payment to the village chief). Interestingly, chiefs are favorably viewed by the majority of the Malawian population. In 2008-2009, 74\% of Afrobarometer respondents in Malawi perceived traditional leaders as having "some" or "a great deal" of influence, and $71 \%$ thought the amount of influence traditional leaders have in governing the local community should increase - for comparison, the average across 19 African countries for these two questions were both $50 \%$ (Logan, 2011). Possibly as a result of this high popularity, chiefs appear able to influence local villagers on whom to support in general elections and local government elections (Patel et al., 2007), an influence that may limit their accountability to elected representatives.

\footnotetext{
${ }^{5}$ In 2014, a village chief in Malawi received 2,500 MWK (about US\$6 in 2014) per month as mswahala, around a week's worth of labor at the prevailing casual wage.
} 


\subsection{Subsidy Programs}

\subsubsection{Fertilizer Subsidy Program}

Malawi's Farming and Agricultural Input Subsidy Program (FISP) is one of the largest fertilizer and seed subsidy programs in the world $[6$ Though the program has existed since 1998, it greatly expanded after a drought in 2004 and has steadily increased in size since then. In 2012-13, the program reached 4.4 million recipients and took up 10-15\% of the government's budget (Dorward et. al 2013, Baltzer and Hansen 2011). In our data, the percentage of people benefitting from subsidies has increased steadily over time, from $63 \%$ in 2008 to $82 \%$ in 2012 .

The subsidy program covers several inputs and comes in the form of vouchers, which are redeemable at a local agricultural shop in exchange for the items. The four most common items covered by the voucher subsidy during our study period were planting fertilizer (a 50 kilogram bag of NPK, worth about $\$ 40$ at market prices in 2013), top-dressing fertilizer (a 50 kilogram bag of Urea, comparable in price to NPK), hybrid maize seeds (a $5 \mathrm{~kg}$ bag, worth about $\$ 7$ ), and hybrid groundnut seeds (a $2 \mathrm{~kg}$ bag, worth $\$ 2.60$ ). The price of the voucher is only $\$ 1.7$, so the subsidy is extremely high, at over $98 \%$, and as a result take-up of the vouchers is reported to be $100 \%$.

There is no strictly defined, official eligibility criteria for the subsidy, but the intention is to target the poor and vulnerable. The official FISP guidelines reads that beneficiaries "will be full time resource poor smallholders Malawian farmers" but no threshold is provided for what defines "resource poor". The program guidelines does hint at particular groups however: "...the following vulnerable groups should also be considered: elderly, HIV positive, female headed households, child headed households, orphan headed households, physically challenged headed households and heads looking after the elderly and physically challenged" (MoAFS 2009).

The identification of beneficiaries has three main stages (Chirwa et al. 2010). First, the government conducts a national farmer registration census. Second, the central government allocates vouchers to districts as a function of the area's farming population and the acreage under cultivation. Within each district, the District Agriculture Development Office (DADO) allocates vouchers across villages based on farming population shares (Chirwa and Dorward 2013). Finally, within each village, once the number of subsidies available to the village is known, a list of eligible villagers is made. Formally, the selection of beneficiaries at this stage

\footnotetext{
${ }^{6}$ Fertilizer subsidies are one of the more popular (and expensive) aid programs across the developing world, in some cases taking up significant fractions of government budgets. For example, Sri Lanka, Malawi and India spend 10-20\% of their government's budget on fertilizer subsidies (Wiggins and Brooks 2010). The countries of Zambia and Tanzania also devote 1-2\% of their budget to subsidies (Baltzer and Hansen 2011).
} 
is supposed to be done by the Village Development Committee through open community meetings, and audited by the DADO. However, as we will show below, most authority appears to be de facto delegated to chiefs.7 Once the list of beneficiaries have been received by the DADO, it establishes a date and venue for the distribution of the vouchers themselves. The distribution is done by a staff member from the DADO. Listed beneficiaries have to show their voter registration card in order to receive the vouchers and also to redeem the vouchers at the retail stores (MoAFS 2009).

The identification of beneficiaries and distribution of vouchers is timed to precede the main planting season (which begins in November and lasts until the harvest in March). Beneficiary lists are typically drawn in August, while the subsidy vouchers themselves are distributed in September/October, in advance of planting.

\subsubsection{Food Subsidy Program}

Malawi devalued its currency in 2012, causing inflation of 20-30\% in 2012-13 (World Bank 2015) and making food imports prohibitively costly. There was also a drought in 2012, causing the harvest to be poor. In response, a food subsidy program was implemented in late 2012, lasting from November 2012 to January 2013. In our area of study, the subsidies were distributed in kind. As with the input subsidy, the program was targeted at the "poor" but without a precise threshold or formula for what constitutes poverty. Of those receiving the subsidy in our data, the average amount received was $103 \mathrm{~kg}$ of maize, $14 \mathrm{~kg}$ of soy blend, $18 \mathrm{~kg}$ of pigeon peas, $10 \mathrm{~kg}$ of beans, and 3 liters of oil. We estimate that this package was worth about $\$ 72$ in 2013 USD. As with the farming input subsidy program, chiefs were given primary responsibility for identifying which households should receive the food aid.

\section{Data}

\subsection{Sample}

The data we use for this paper was collected as part of a separate research project focused on estimating the impact of providing savings accounts to unbanked households (Dupas et al., 2017a). The project took place around the catchment areas of NBS bank branches in two districts of Southern Malawi - Machinga and Balaka. The sampling frame for Dupas et

\footnotetext{
${ }^{7}$ For example, Dorward et. al (2013) show that around 70\% of households in 2013 believed the decision on voucher recipients was made by the chiefs before the official meeting was held.
} 
al. (2017a) relied on a census of market businesses and a census of households - we use only the household sample for this analysis. The household census listed 9,297 households from 68 villages in three Traditional Authorities (TA) areas - Kalembo, Sitola, and Nsamala. Of these, $78.8 \%$ met the eligibility criteria set by Dupas et al. (2017a): they did not have a bank account and had a female head. Dupas et al., 2017a randomly sampled a subset and completed 2,107 baseline surveys. Of this baseline sample, 354 did not complete one of the three follow-up surveys used in this paper (16.9\%). In addition, the module to measure food subsidy receipt was introduced only partially through the endline survey, and another 185 households were not asked these questions (9.7\%). We are thus left with a sample of 1,568 households. The analysis in this paper requires comparing subsidy recipients to nonrecipients in the same village, so we need a sufficient number of people in each village. For this reason we drop five villages with less than 5 households in our data, and are left with 1,559 households in 61 villages for our analysis.

This sampling frame creates two issues for the analysis in this paper. First, our data includes only a subset of people in each village (around 10\%). Since our question of interest is to understand how chiefs allocated subsidies within this sample, and our basic thought experiment is to ask what the gains would be from re-allocating subsidies within this sample, our results are still internally valid and of interest, however. Second, our sample is selected on not having a formal place to save. Since poorer people are less likely to have an account, it is likely that our sample is poorer than average. We may therefore underestimate overall targeting errors (if any of the relatively better-off people with bank accounts ended up receiving subsidies).

\subsection{Data Sources}

Household Panel We have four waves of survey data for each household in the sample: (1) a baseline conducted from January to March 2011 (2) a first follow-up survey conducted from January to March 2012; (3) a second follow-up survey conducted from September to November 2012; and (4) an endline survey conducted from January to March 2013. The baseline survey includes a standard set of demographic variables, including a module on asset ownership which can be used to construct the allocation that would have obtained under a counterfactual allocation based on a proxy-means test from baseline assets. Each of these survey rounds included detailed expenditure modules.

The follow-up and endline surveys include a module on the farming subsidy. This is used

to construct a time series of subsidies received from 2008-2013, for each household. The module includes information on which input subsidy was received, whether the household 
received the voucher itself or shared another household's voucher, and what the household actually did with the subsidized products (used them, sold them, shared them, etc.). The endline survey also asked these questions for the food subsidy, which was introduced in 2012. Finally, the endline included a separate module with questions on how the input and food subsidies were allocated. These include questions on how (in the respondent's opinion) the vouchers were allocated, whether a public meeting was held, whether the respondent participated in the meeting, etc. We use this module to provide some descriptive evidence on how the programs were implemented.

In addition, between August and October 2014 we collected a fifth wave of data for a random subset of 563 households in the initial sample. This survey asked additional questions on the process through which subsidies were allocated and on respondents' attitudes towards the allocation process as well as their perception of the traditional authorities' role, beliefs and objectives in this allocation. Importantly, we also elicited households' beliefs on the returns to farming inputs on their own land.

Chiefs Survey Between August and October 2014 we collected surveys with all of the 105 traditional leaders in our study area of 61 villages, including 76 village headmen (chiefs) and 29 group village headmen (GVH) 8 The survey included questions on their tenure and responsibilities, and included questions about the details of how the FISP and Food subsidy programs were allocated. We also measured village chiefs' self-reported knowledge of the distribution of returns to inputs in their village, and of the realizations of household-specific shocks.

\subsection{Characteristics of households, chiefs and villages in the sample}

Table 1 presents basic summary statistics on the households in our sample. Panel A includes time-invariant characteristics collected at baseline. The first variable shown is the household's self-reported relationship to the chief. We asked the following question to each respondent: "Are you related to the chief?," to which $27 \%$ reported yes. In a follow-up question, we asked: "How are you related?" The modal answer was the chief is an uncle ( $20 \%$ of the related cases), followed by brother (13\%), brother-in-law (12\%) and grandfather $(12 \%)$. In what follows, we refer to those who reported as being related to the chief as "kin" ?

\footnotetext{
${ }^{8}$ The reason why there are more chiefs than villages is that 19 villages were divided into multiple villages between our initial data collection in 2011-13 and the time of the survey in 2014.

${ }^{9}$ Given an average village size of 300 households (Table A1), the numbers imply that in an average village the chief is uncle to 16 heads of households, the brother to 11 households, the brother in law to 10 households, and the grandfather to 8 households. While high, these numbers are not implausible given high fertility rates.
} 
Households in the sample are very poor: $90 \%$ have mud floors or worse quality, $77 \%$ have thatch roofs, and less than $1 \%$ have electricity. Only $59 \%$ are literate, and average years of education for the household head is just below $51^{10}$ The FISP program specifically targets single-headed households (the majority of which are widowed women), and there are a large number of these: $28 \%$ of households are headed by females alone. Ninety-seven percent of households in our sample own some land.

Panel B shows time varying expenditure, shocks and transfers. Across rounds, households report spending a total of only $\$ 9.66$ per month per capita, $\$ 6.80$ on food, and $\$ 2.71$ on nonstaple food. These figures place these households well below the global extreme poverty threshold of $\$ 1.25$ per day. Shocks are also quite common: $26 \%$ lost at least 1 day of work in the past month due to illness, $69 \%$ had another household member sick over the past month, 28\% experienced a drought or flood, and 20\% experienced crop loss or livestock death. Across survey rounds, $72 \%$ of households report being worried about having enough food to eat in the past 3 months. Transfers across households within the village are very common, with $58 \%$ of households reporting being recipients of transfers in the last 90 days, and $25 \%$ reporting having made transfers.

Columns 3 and 4 of Table 1 show, for each variable, the gap between kin and non-kin and its standard error. This reveals that if anything, kin are poorer than non-kin - they are significantly less educated (Panel A), and have slightly lower consumption (Panel B). The only dimension in which they appear better off regards land ownership, which likely comes from the fact that chiefs' primary official responsibility concerns customary land allocation.

Not only are households in our sample poor, they area also facing a lot of variation in resources over time. Column 5 of Table 1 presents the correlation between survey rounds for the variables in Panel B. In general, the correlation is fairly low: shocks are largely uncorrelated across rounds, and the correlation for our neediness measure, non-stable food expenditure, is just 0.35 . The correlations for chiefs' kin are not higher than for the overall sample, suggesting that chiefs' kin do not face less risk.

Table A1 presents summary statistics on villages and village chiefs in our sample. The average village in our sample has 340 households and over 7,000 acres of customary land.The average village chief is 53 years old and has just over 5 years of education. Eighty two percent of chiefs are male. They have been chief for 13 years on average, and 90\% inherited the position (most of the remainder were appointed). The vast majority faced no competition from within the family blood line for the position. In principle, traditional leaders can be removed from office or reprimanded, but our data suggests this almost never happens: only one of the chiefs we surveyed mentioned having ever been suspended. These basic statistics

\footnotetext{
${ }^{10}$ The school system in Malawi is composed of 8 years of primary school and 4 years of high school.
} 
suggest that chiefs are de facto not accountable to anyone.

When chiefs were asked about their main responsibilities, the five most common responses were resolving conflicts among villagers (90\%); reporting issues to higher level chiefs $(61 \%)$; monitoring village projects (56\%); disseminating information to villagers (33\%); and overseeing subsidy programs $(20 \%)$.

\subsection{Summary statistics on the allocation of subsidies in our sample}

Table A2 presents summary statistics on the process through which input and food subsidies were allocated among households in our sample. Panels $\mathrm{A}$ and $\mathrm{C}$ rely on the latest round of survey data (2014) and presents evidence on how both chiefs and villagers experience and perceive the subsidy allocation mechanisms. Panel B presents data from the earlier household survey waves.

The data confirms that chiefs are the primary decision-makers in allocating subsidies. Turning first to panel A, the great majority of village chiefs report that they have control over the subsidy allocation: $62 \%$ declare deciding by themselves, and an additional $3 \%$ report deciding in collaboration with others. Of the remainder, $13 \%$ report that the village development committee (of which the chief is a member) decides the allocation, and $13 \%$ report that subsidies are allocated in a village meeting (which the chief typically runs). When asked about selection criteria, chiefs report need as the primary criterion. Chiefs also put significant weight on female-headed households, households which recently received a shock households taking care of orphans, and households that the chief believes are hard-working.

Panel B suggests that community meetings regarding the selection appear to happen quite regularly, with approximately $95 \%$ of villagers reporting that a meeting was held to discuss input subsidies, and high attendance at the meeting ( $82 \%$ for inputs and $65 \%$ for food subsidies). Nevertheless, Panel $\mathrm{C}$ shows that households report that the village chiefs

has a considerable role in the allocation: $49 \%$ report that the chief alone decides on the input subsidies, and $73 \%$ report that the chief alone decides on the food subsidies. Like chiefs, households list neediness as the main criterion, but they also mention demographic characteristics of the household (elderly and female headed households, which are considered priority households in the allocation due to increased neediness). The great majority of households perceive the allocation of subsidies as "very good." There seems to be two factors that households consider when deciding whether the allocation is good - one is whether the allocation benefits the poorest, and the other is whether the allocation reaches the largest possible share of households. The concern for reaching as many households as possible is echoed by chiefs: when asked how they would allocate additional vouchers if they were to 
receive them, all but one chief say they would give vouchers to more households so that the number of beneficiaries expand (Panel A).

This relates to an important fact about the allocation of subsidies that transpired from our data: while the FISP guidelines do not endorse sharing of subsidy packages, in practice sharing is quite common. We show this in Table A3. Villagers report large levels of sharing, primarily orchestrated by the chief. Seventy-seven percent $(0.46 / 0.60)$ of households who received a subsidy voucher report sharing it; of those $83 \%$ say they received instructions from the chief on whether to share it, and $79 \%$ received specific instructions from the chief on whom to share with. They also overwhelmingly report that the chief decides how food subsidies are shared.

Table A3 also shows summary statistics on subsidy receipt. The percentage of households receiving input subsidies has increased steadily over time, from $58 \%$ in 2008 to $81 \%$ in 2012 . Receipt of the input subsidy is quite correlated over time, with $48 \%$ of households receiving some input subsidy in all five years covered in our data, and 10\% never receiving any input subsidy. Conditional on receiving the subsidy, the quantity of fertilizer received (summing over the two types of fertilizer, for planting and top-dressing) was about 77 and $64 \mathrm{~kg}$ during 2011 and 2012 respectively. This is smaller than the official package that subsidy beneficiaries are entitled to get $(100 \mathrm{~kg})$ due to sharing. Sharing seems to increase over time, explaining part of the growth in the coverage rate: in 2012, more households receive some subsidized inputs but they receive smaller quantities. The food subsidy of 2012 was more limited in scope than the input subsidy, reaching only $59 \%$ of households, though sharing was common for food as well 11

Since our aim is to think about the efficiency of the chief's allocation, in what follows we consider the allocation observed in our data after sharing. That is, if a household answered "yes" to the question "Did you receive an input (food) subsidy in that year?", we consider this household as a beneficiary, irrespective of whether, in subsequent survey questions, the households reveals that it did not receive the actual voucher but a share from another household instructed to share their voucher.

\section{Other safety net programs}

Beegle, Galasso and Goldberg (2015) document that chiefs are also involved in deciding which households are eligible for Malawi's public work program (PWP) - though the responsibility falls more on the Group Village Headmen and the villagers themselves. They report that Malawi's PWP "has been operational since the mid-1990s and aims to provide short-term

\footnotetext{
${ }^{11}$ In $2012,53 \%$ of households received both the input and food subsidy, $13.6 \%$ received neither, $5 \%$ received the food subsidy only and $27.9 \%$ received the input subsidy only.
} 
labor-intensive activities to poor, able-bodied households for the purpose of enhancing their food security." While we unfortunately did not collect data on participation in the PWP directly from respondents in our surveys, a fuzzy name match between the original household sample and administrative data on PWP participants obtained from the two districts in our sample yields 167 matches for the 2012-2013 budget year, out of 2,107 households in the Dupas et al. (2017a) baseline survey, suggesting that the PWP coverage in our study area is about $8 \%$. Verification surveys with a subset of those matched and unmatched conducted in March 2015 suggests that an additional 3\% may have been participating in PWP, bringing our estimates to roughly 11\%.12 While name matching is always prone to significant error, this ballpark figure is not far from the $15 \%$ coverage targeted by the program. While studying how the PWP is targeted and the specific role of chiefs would have been interesting, omitting it due to data limitations should not affect our analysis of the other subsidy progams. Notably, Beegle, Galasso and Goldberg (2015) find no correlation between receipt of PWP and receipt of other benefits, suggesting no strategic allocation across programs, in particular, no compensation of non-PWP households with input or food subsidies.

\section{Poverty targeting}

\subsection{Measuring Neediness}

To measure neediness, we follow Alatas et al. (2012) and use whether households would have qualified based on their food expenditure distribution, which we consider a proxy for consumption. Food expenditures have been shown to be better predictors of neediness than other measures such as income (Deaton 1997; Meyer and Sullivan 2012).

While there are 12 total food categories measured in each survey wave, we focus on the 10 categories that are typically purchased rather than self-produced. These are all but the staples and grains: vegetables, fruits, meat, dairy/eggs, salt, sugar, other cooking items (oil, margarine), coffee and tea, snacks, and juice/sodas. Ligon (2016) identifies those foods as elastic goods among a similar population of households in Uganda, and thus useful for drawing inferences regarding household's marginal utility of contemporaneous expenditures, or neediness. The two categories excluded were recorded in the survey as "staple" and "grains/nuts", which the great majority of household produce for home consumption 13

\footnotetext{
${ }^{12} \mathrm{We}$ are extremely grateful to Santiago Saavedra for obtaining the administrative records and performing the matching analysis and verification surveys.

${ }^{13}$ We expect expenditure to be negatively rather than positively correlated with total consumption for such goods.
} 
We compute the sum of expenditures on these 10 food categories over the 30 days preceding the survey and then divide the sum by the number of household members to construct "per capita non-staple food expenditure" or PCF, our measure of need going forward (we report this figure in USD) 14 The distribution of log PCF in our data is plotted separately for the two main years of analysis, 2011 and 2012, in the top panel of Figure A1.

Timing The food expenditure we would ideally use to determine "true need" (PCF eligibility) would be measured right around the time when subsidy beneficiaries are identified (which is around August for the input subsidy and November for the food subsidy). However, the timing of our surveys does not precisely correspond to these periods. Our food expenditure module covered the last 7-30 days (depending on the question) before the survey date. Thus, given the dates of the surveys mentioned in Section 3.2, we have consumption data for the following periods: December 2010 to February 2011; December 2011 to February 2012; August to October 2012; and January to March 2013. To study the targeting of the 2011 input subsidy, we thus have to rely on the December 2010 to February 2011 expenditure data, which is not ideal because it is substantially before the period of interest. In particular, it is before the March 2011 harvest, which is likely an important determinant of actual neediness as of August - October 2011.15 This is less of a concern for the 2012 subsidies, where we have consumption data from August to October, which is concurrent with the identification of beneficiaries and exactly precedes any actual distribution of food.

\subsection{Constructing counterfactual allocations}

\subsubsection{Neediness Rank}

For each village, we observe the total number of households within our sample who benefited from a subsidy (be it full or partial) - call this number $\bar{s}$. To construct the counterfacult in which vouchers (voucher shares) were distributed based on true consumption, we rank households (within each village) by their per capita non-staple food expenditure (PCF). We consider a household "PCF eligible" if they are ranked at or below the $\bar{s}$ th farmer in the PCF distribution. We break ties based on total food expenditures and then total expenditures on

\footnotetext{
${ }^{14}$ We choose to compute things per capita (PC) rather than per adult equivalent (PAE) because commonly used equivalence scales between children and adults may be an underestimate of how much communities actually value children consumption (Olken 2005). We have done the entire analysis in the paper using PAE instead of PC and the results are identical. See Deaton and Zaidi (2002) for a discussion of constructing poverty indices.

${ }^{15}$ We could possibly use the December 2011 to February 2012 data since no food subsidies were distributed that year and the proceeds of the maize planted with the subsidized inputs of 2011 were not reaped until March 2012. We have run the analysis for 2011 this way and the results are very similar.
} 
all items.

\subsubsection{PMT Score Rank}

To construct the counterfactual in which voucher shares were allocated via PMT, we repeat this procedure but this time we rank households (within each village) by a "PMT score". We consider households PMT eligible if they are ranked at or below the $\bar{s}$ th household in the PMT score distribution. We compute the PMT score as follows: we regress log PCF on household characteristics, including demographic characteristics, dwelling characteristics, assets and occupation, and use the estimated coefficients to predict a score for each household. As in Alatas et al. (2012), we do this in two steps: we first run kitchen sink regressions with all available characteristics and then, using a backward stepwise procedure, keep only those characteristics significant at the 10 percent level in the regression used to predict the score.

The PMT regressions are shown in Table A4. We show the results for both per capita and per adult equivalent food expenditure, and find slightly higher predictive power for per capita values ${ }^{16}$ From Column 1, we obtain a R-Squared of 0.32 , which is somewhat lower than the 0.40 obtained by Alatas et al. (2012) in Indonesia (when pooling districts together). To test the extent to which our lower R-Squared is due to a particularly pronounced measurement error problem in our dataset, in Table A5 we use data from the third wave of the Integrated Household Survey (IHS3), a representative household survey collected by Malawi's National Statistics Office. We restrict that dataset to the two districts in our sample, and estimate PMT regressions using the same backward stepwise method to identify covariates. We obtain a R-Squared of 0.39 when we include all potential covariates available in the IHS3, and essentially the same when we restrict the potential regressors to the set available in our own dataset (we call it "BDR variables," with slightly different variables than the IHS3). This suggests that the lower R-Squared we obtain in our own dataset is not due to our survey instrument having failed to measure important predictors. Instead, our R-squared of 0.32 in our dataset is possibly lower than the 0.39 found in IHS3 data because our sample is somewhat poorer than a representative sample, and their consumption may be more volatile due to lower access to insurance. In comparable samples from neighboring countries we find similarly low R-squared values: Table A6 shows regressions for samples of rural unbanked households in Kenya (Dupas et al., 2017b) and Uganda (Dupas et al., 2017a). We find an R-squared of 0.31 in Kenya and 0.28 in Uganda.

\footnotetext{
${ }^{16}$ We use a per adult equivalent formula of 1 child under 18 equal to 0.5 adults.
} 


\subsection{Poverty-targeting results}

\subsubsection{PMT vs. Chief Allocation}

Our first main result is Figure 1, which plots the probability of receiving the subsidies by quintile of the PMT score distribution (top panel) and quintile of the PCF distribution (bottom panel). We show the "true" allocation (made by the chiefs, solid line) as well as two counterfactual allocations: the PMT allocation, our "benchmark" for what could be done under centralization; and the PCF-based allocation, the "optimal" allocation from the point of view of need targeting. We pool across villages, which vary in their underlying distributions as well as in the number of subsidies available, which explains why neither of the two counterfactual allocations are perfect step functions of their respective distributions. It also explains why even the PCF-based allocation does not reach perfect targeting: there appears to be substantial mistargeting across villages which explain that even a perfect allocation within village would yield evidence of mistargeting on Figure 1 since it is aggregated across villages. The PCF gradient of PCF-based allocation in Figure 1 should therefore be considered as the "best possible targeting" given the across-village allocation in our data.17

From the top panel, it is clear that chiefs target different people than the PMT would: while the PMT, by definition, would allocate subsidies to $100 \%$ of people at the bottom of the distribution, the chiefs' allocation has a much flatter gradient with respect to the PMT score. In isolation, this result looks similar to Dorward et al. $(2008,2013)$ and Kilic et al. (2013), who look at how well chiefs target based on assets and conclude that there is widespread mistargeting.

The bottom panel, which show targeting based on PCF, also show that the PMT does better than chiefs - but the gap is much smaller than in the top panel. In the allocation decision of 2011, contemporaneous to the PMT formula data collection, the gradient for the PMT allocation is quite a bit steeper than that of the chiefs, but by 2012 a lot of the PMT edge has ebbed already, suggesting that the advantage of the PMT may be short-lived. While the PMT does better than the chiefs at least initially in terms of poverty-targeting, it still generates a substantial number of errors. This is true even if we use the PMT formula from the IHS3 rather than the one derived in our dataset (see Figure A3). The relatively poor targeting performance of the PMT seems due to the fact that assets (the most important factor in the PMT) are a relatively poor proxy for need in our study context, because PCF eligibility is not time-invariant (the correlation between food expenditures across rounds is only 0.35 as previously discussed and shown in Table 1) and because there are important

\footnotetext{
${ }^{17}$ While understanding the determinants of subsidy allocations across villages is of great interest, our data does not allow us to study this question.
} 
unobservables in the determinants of PCF.

One concern is that part of the variation across periods and unexplained variation across households could come from measurement error in food expenditures. Such measurement error would flatten the gradient in PCF for both the chiefs and the PMT. In Table A7 we show that our measure of non-staple food expenditure in the past month is significantly correlated with self-reported food security: a log point increase in PCF corresponds to a 4 percentage point (15\%) decrease in the share of days without enough food and a 5 percentage point $(15 \%)$ increase in the likelihood of not being worried about having enough food.

\subsubsection{Error rates}

Table 2 shows the poverty-targeting error rate under the two allocation schemes (chiefs and PMT). The table shows the average village error rate (averaging first over individuals within villages, and then across villages). For these calculations, we include only those villages in which the probability of getting a subsidy is between 0 and 100\% (so that targeting errors are possible) 18 Following Alatas et al. (2012), what we call the poverty-targeting error rate is the probability that a household is (1) eligible based on its position in the PCF distribution within the village; but (2) does not make it onto the actual beneficiary list (chief error) or on the counterfactual PMT beneficiary list (PMT error). Note that since the number of beneficiaries within the village is kept fixed in this exercise, this error rate also provides the probability that a household is (1) categorized as ineligible based on its position in the PCF distribution and (2) gets the subsidy. In other words, mechanically there are as many people who don't get the subsidy when they should (exclusion errors) as there are people who get the subsidy when they should not (inclusion errors). We also show what the expected error rate would be if subsidies were allocated randomly. These are calculated from a permutation test with 1,000 draws (the distribution of results for those are shown in Figure A2). Finally, we also compute the squared error for each allocation.

We can see that both allocations make a significant number of errors compared to the PCF-based allocation, but that the PMT always performs better for input subsidies. The average error rate for the PMT is $10-12 \%$, compared to $14-16 \%$ observed by chiefs (these differences are statistically significant). Perhaps a better metric for measuring error is mean squared error, which punishes error far from the eligibility threshold more than errors closer. We again find strong evidence that the PMT does better. Note that we consider somewhat of a "best-case" PMT: we assume perfect compliance with the allocation rule, ignoring poten-

\footnotetext{
${ }^{18}$ The table reports the probability of all or none of the villagers getting the subsidy. The odds that all villagers got the subsidy was $9,8 \%$ for the 2011 input subsidy, $14.8 \%$ for the 2012 input subsidy, and $4.9 \%$ for the 2012 food subsidy. In addition, the food subsidy was not given out in $4.9 \%$ of villages.
} 
tial implementation issues; what's more, our PMT formula is based on data that predates the consumption and subsidy allocation measures by only a year, while any actual PMT allocation rule would likely rely on older data in most years (since measuring household-held assets, a key component of the PMT formula, is costly, especially once households know their eligibility depends on their survey responses - see Besley 1990).

While chiefs do worse than the PMT, they do not seem to make random allocations (see Table 4 and Figure A2). The simple error rate for the input subsidies is clearly worse than would most likely be obtained from random targeting (see Figure A2), though- the mean squared error is much lower, suggesting that chiefs trade PCF_eligible for ineligible only around the PCF cutoff. Chiefs, in contrast, do better than random on the food subsidy, by both metrics.

Thus an interesting pattern in these results is that chiefs look worse at targeting the truly needy for the input subsidy than the food subsidy. A central hypothesis of this paper is that this may be due to productivity targeting of the input, which we will argue is less relevant for food. We will return to this issue in detail in Section 5.

\subsubsection{Who is favored and who is left out by chiefs?}

Table 3 shows the results of a multivariate regression of subsidy receipt on background characteristics and village fixed effects. We show the covariates of actual receipt (the true allocation, made by the chiefs) in columns 1-4. In columns 5-8 we show the characteristics targeted under the counterfactual PMT. Comparing the coefficient estimates across the two sets of analyses tells us who is favored and who is left out under each scheme. We consider both the extensive margin (receiving any subsidy) and the intensive margin (value of the subsidy received, since this varies across households due to sharing). 19 The first row of Table 3 confirms the poverty-targeting results discussed above: the gradient in PCF is more negative under the PMT than under the chiefs, and the gap in the gradient is more pronounced for the input subsidy than for the food subsidy.

We find evidence of nepotism: conditional on covariates, chief's kin are 11 percentage points more likely to receive the food subsidy under the chief, whereas they would not be favored under the PMT. For the input subsidy, nepotism appears much less pronounced: while chief's kin receive a greater input subsidy package (an extra $3.30 \mathrm{~kg}$ off of a mean

\footnotetext{
${ }^{19}$ For the intensive margin, we construct the counterfactual PMT allocation keeping the distribution of input subsidy values the same as under the chief, but assigning the largest value subsidy to the household with the lowest PMT score, the second largest value to the housheold with the second lowest PMT score, etc. This inflates the targeting performance of the PMT compared to allocating fixed subsidy values to every household eligible. This is the relevant benchmark insofar as there is no reason (other than logistical constraints) why subsidy amounts under the PMT cannot be varying with the PMT score.
} 
of $50.5 \mathrm{~kg}$, significant at 10\%), the PMT would also award kin higher subsidy packages $(+2.3 \mathrm{~kg}$, also significant at the 10 percent level). This is due to the fact that chiefs' kin are marginally asset poorer than non-relatives. Turning to other covariates, we find that chiefs target older households, as per the official FISP recommendation. Chiefs also target households that received negative shocks: households who experienced a drought or flood are 4 percentage points more likely to receive subsidized food, while households who experienced crop loss or cattle death are 8 points more likely to get it.

In sum, the results in Table 3 epitomize the tradeoff between local information and capture: we find that chiefs are able to use local knowledge to benefit households hit by recent negative shocks, while the PMT misses them; but they also favor their kin.

Our finding of nepotism in the allocation of the food subsidy is not unique to Malawi. A review paper by Baltzer and Hansen (2011) of programs in four African countries (Ghana, Malawi, Tanzania and Zambia) finds significant evidence that subsidies disproportionately go to politically connected households. The important question though is whether such nepotism has important welfare consequences. Alatas et al. (2013) show that the "cost" of nepotism in terms of average consumption level among beneficiaries can be approximated with the following formula:

$$
\triangle C=\alpha \frac{\triangle \beta}{\beta} \frac{\left(c_{e}-c_{b}\right)}{c_{b}}
$$

where $\alpha$ is the share of kin, $\frac{\Delta \beta}{\beta}$ is how much more likely kin are to receive benefits, and $\frac{\left(c_{e}-c_{b}\right)}{c_{b}}$ is how much richer kin are. Taking the following values from our data: $\alpha=0.27, \frac{\Delta \beta}{\beta}=0.19$ (for the food subsidy) and $\frac{\left(c_{e}-c_{b}\right)}{c_{b}}=0.053$, we obtain $\triangle C \approx 0.0027$. In other words, nepotism in the allocation of the food subsidy reduces consumption among the truly eligible by $0.26 \%$. This is a very small cost, in fact surprisingly similar to that obtained by Alatas et al. (2013) for Indonesia $(\triangle C \approx 0.003$ for a cash transfer program). The main reason why nepotism is not very costly in terms of consumption targeting is that kin and non-kin are equally poor in our sample. Nepotism could however mean that kin can achieve the same level of consumption alongside much more leisure (if they do not need to work as hard to achieve the consumption). The distributional impacts of nepotism in terms of overall welfare could thus be non-trivial if leisure is valued highly.

\section{$5 \quad$ Productive Efficiency Targeting}

In this section, we investigate whether some of the apparent mistargeting of input subsidies by chiefs is due to targeting on farming productivity: if returns to input subsidies are heterogeneous and chiefs have information on this, then they might allocate subsidies in a 
way that takes both poverty targeting and productive efficiency into account. In this section we present a model that allows for heterogeneity in returns as well as heterogeneity in the welfare weights that chiefs assign to households, and propose a method to test whether the mistargeting we observe for input subsidies is in part driven by productive efficiency considerations.

\subsection{Model and prediction}

We consider the problem of allocating subsidies across households within a village. The intra-village allocation is done by the village chief.

Suppose that allocation of subsidy $s(s \in\{$ fertilizer, food $\})$ to household $i$ enables that household to generate additional income:

$$
y_{i}=A_{i s} s^{\mu}
$$

where $A_{i}$ denotes individual-specific returns to the subsidized resource and $\mu \in(0,1)$ denotes

potentially diminishing returns in the subsidized resource. In the nested special case where the subsidized resource is food, rather than farming inputs, we set $\mu=1$ and $A_{i s}=1$ for all households (and thus start by abstracting away from a case in which there is a productive response to nutrition - we relax this assumption later).

We assume that households share a common homothetic, CRRA utility function defined over total income:

$$
u_{i}=\frac{\left(y_{i}+e_{i}\right)^{1-\rho}}{1-\rho}
$$

with $\rho>0, \neq 1$ and where $e_{i}$ is the income that household $i$ gets in addition to the subsidyenabled income.

The aggregate supply of subsidies to the village is denoted by $\bar{s}$. Under a proxy-mean test, the subsidies would go to the $\bar{s}$ households in the village with the lowest PMT score. In contrast, when allocating subsidies across households within the village, and assuming for now that there is no ex post redistribution orchestrated by the chief, the chief chooses the subsidy levels $s_{i}$ so as to maximize the weighted sum of villagers' utility:

$$
\sum \omega_{i} \frac{\left(A_{i s} s_{i}^{\mu}+\hat{e}_{i}\right)^{1-\rho}}{1-\rho}
$$

subject to

$$
\sum_{i} s_{i}=\bar{s}
$$

In equation $1, \hat{e}_{i}$ is the income that the village chief expects household $i$ to have at the time 
the subsidy benefits are realized, and $\omega_{i}$ is the relative welfare weight of household $i$. Since chiefs do not face reelection incentives and have limited accountability (see section 2.1), the relative welfare weight of a household may not reflect its role in the political process as in earlier models (Bardhan and Mookherjee, 2000, 2003, 2006) but may instead depend on the preferences of the chief (e.g. if the chief favors his kin, the relative welfare weight of kin will be higher).

While $\hat{e}_{i}$ could be endogenous, we assume that the chief can take the households' best response distribution of $\hat{e}_{i}$ as given when maximizing the objective function shown in 1 .

Taking the first order conditions for input subsidies $(s=f e r t)$ for two households $i$ and $j$ yields:

$$
\omega_{i}\left(A_{i} f e r t_{i}^{\mu}+\hat{e}_{i}\right)^{-\rho} A_{i} f e r t_{i}^{\mu-1}=\omega_{j}\left(A_{j} f e r t_{j}^{\mu}+\hat{e}_{j}\right)^{-\rho} A_{j} f e r t_{j}^{\mu-1}
$$

For food subsidies, where $A=1$ and $\mu=1$ for all households, we have an analogous but simplified expression:

$$
\omega_{i}\left(\operatorname{food}_{i}+\hat{e}_{i}\right)^{-\rho}=\omega_{j}\left(\operatorname{food}_{j}+\hat{e}_{j}\right)^{-\rho}
$$

Taking the ratio of 2 over 3 , the welfare weights cancel and we obtain:

$$
\frac{\left(A_{i} \text { fert }_{i}^{\mu}+\hat{e}_{i}\right)^{-\rho} A_{i} \text { fert }_{i}^{\mu-1}}{\left(\text { food }_{i}+\hat{e}_{i}\right)^{-\rho}}=\frac{\left(A_{j} \text { fert }_{j}^{\mu}+\hat{e}_{j}\right)^{-\rho} A_{j} \text { fert }_{j}^{\mu-1}}{\left(\text { food }_{j}+\hat{e}_{j}\right)^{-\rho}}
$$

From this expression we can derive the relationship between a household's productivity parameter $A_{i}$ and the difference in value between the fertilizer and the food subsidy that that household receives $\left(\right.$ fert $_{i}-$ food $\left._{i}\right)$. In Figure A4, we plot that relationship setting $\mu=0.9$ and either $\rho=0.5$ or $\rho=1.2$. The relationship is positive: as the returns to fertilizer increase, a household receives relatively more fertilizer subsidies than food subsidies. The intuition here is the following: if productivity considerations matter, then if a household has a higher return to the fertilizer subsidy than average, then that household should be relatively more favored when it comes to the input subsidy than for the food subsidy. Unsurprisingly, when the utility function is very concave $(\rho=1.2)$, the impacts of productive efficiency considerations is considerably muted, since increases in the resources of the already better off have lower value.

This leads us to the prediction we can test in the data:

Prediction If chiefs take into consideration productive efficiency when allocating farming subsidies, $d\left(\right.$ fert $_{i}-$ food $\left._{i}\right) / d A_{i}>0$. Namely, the higher the return to fertilizer for a household, the higher the gap between fertilizer and food subsidies received by that household. 
Below we show that this prediction holds under a number of extensions to the basic model.

Allowing chiefs to orchestrate transfers As shown in Table 1 Panel $\mathrm{C}$, there is a significant amount of transfers between households within the village. In the presence of a redistribution instrument, the chief's objective function would be modified as follows: the chief now chooses the sets of subsidies $s_{i}$ and transfers $t_{i}$ so as to maximize:

$$
\sum_{i} \omega_{i} \frac{\left(A_{i} s_{i}^{\mu}+t_{i}+\hat{e}_{i}\right)^{1-\rho}}{1-\rho}
$$

subject to

$$
\begin{aligned}
& \sum_{i} s_{i}=\bar{s} \\
& \sum_{i} t_{i}=0
\end{aligned}
$$

where $t_{i}$ is the net ex-post income transfer received by household $i$, which can be either negative or positive.

It is evident that redistribution will allow chiefs to target productivity more than the autarkic case. Thus the more rdistribution is possible, the greater the optimal wedge between the fertilizer and the food subsidy a given household receives. In the extreme case in which income is fully pooled, the objective function of the chief can be rewritten as $\max \sum_{i} \beta_{i}\left(A_{i} s_{i}^{\mu}\right)$. In this case, the allocation of fertilizer subsidies will be entirely driven by productive efficiency since redistribution will happen ex post 20

Productive response to better nutrition It is possible that food subsidies increase productivity for very poor households due to improved nutrition (Strauss, 1986). Such a nutrition-productivity link would not change the prediction. To see this, note that allowing for the efficiency of an hour worked to increase with food subsidies implies a negative correlation between the relative productivity of inputs and the relative productivity of food,

\footnotetext{
${ }^{20}$ The two subsidies we study could be complementary: the input subsidy as a growth instrument and the food subsidy as a redistribution instrument. This is an interesting insight which suggests that the introduction of the food subsidy may lead to an increase in the extent to which the input subsidy can be used by chiefs as a growth instrument going forward. Note that this does not invalidate our test: since the food allocation at any point in time should be based on the pareto weight and current consumption irrespective of whether the current consumption level was secured through enhanced yields in the previous period thanks to inputs subsidies or not - relative pareto weights can still be backed out from jointly observing the food allocation and current consumption, as we do. Also, in our data, the food subsidy was announced after the 2012 input subsidy allocation had been decided.
} 
given the complementarity between farm inputs and efficient labor units. This increases $d($ fert - food $) / d A$.

Price effects In many African countries, rural economies are poorly connected to markets and thus local prices may be responsive to local output. If so, allocating subsidies to the most productive may reduce prices by increasing output. Since $90 \%$ of farmers in our sample are net buyers of grain (in other words, they consume more grain than they produce), such a price effect would translate into a positive income effect for most villagers and thereby increase welfare. This increases $d$ (fert - food $) / d A$ for any $\rho$ because allocating inputs to households with higher returns increases the welfare of the rest of the village through lower prices.

\subsection{Results}

To test the prediction, we need to exploit cross-sectional variation in $A$, the household (farm) specific productivity of fertilizer. This information was not collected as part of the savings project (Dupas et al., 2017a) that generated our core dataset, so we collected this data in the fifth survey round conducted in the summer 2014. Due to budget constraints this survey was done with only a random subset of households in each village, so the sample size for this analysis is about $1 / 3$ of the initial sample size. In the survey, we asked respondents to estimate the output they would get on their land both with and without fertilizer. We show these means in panel $\mathrm{C}$ of Table 1 , and we plot the distribution of the reported gain in total output in Panel B of Figure A1. There is substantial heterogeneity in these reported gains from input use. What drives it? Table A8 examines correlates of yield increases with inputs. We regress the log yield increase on log acres and other observables. We find that yield increases are correlated with many variables, including household demographics (yield increases are increasing in the age of the head of household), education, log assets, and household size (though this is not statistically significant). We expect that these are the types of proxies that the chief may use to allocate subsidies, in addition to other characteristics that are unobservable to us, such as land quality. Also of note is that the correlation between estimated production gains from using fertilizer are and our measure of neediness, PCF, is fairly weak (Panel C of Figure A1). We also find no systematic differences by kinship status (Table 1 Panel C, column 3, and Table A8).

To test for productive efficiency targeting, in Table 4 we regress the value of the fertilizer and food subsidies received, as well as their gap $\left(\right.$ fert $_{i}-$ food $\left._{i}\right)$, on the log of reported gains in output when using fertilizer. We find clear evidence in favor of targeting based

on productive efficiency: the value of the input subsidy received increases significantly with 
the reported gains from fertilizer use. The food subsidy, by contrast, is not correlated with gains. When we look at our primary outcome - the gap betwen the two - we find that the gap increases significantly with the gain from fertilizer, as predicted by the model. In Figure 2 we plot the estimated relationship between the subsidy values and the gain when using a quadratic instead of log. The positive slope for input subsidy values under the chief's allocation is very clear, compared to the flat relationship for food subsidies.

These results are in sharp contrast with those for the counterfactual PMT distribution, in which the value of the subsidy is actually (insignificantly) declining in the gains to fertilizer (because of a negative correlation between returns and assets). In that case, the PMT undermines the effect of the subsidy on total farm output at the village level. In contrast with the chief's allocation, the gap between fertilizer and food subsidy values does not significantly increase with reported gains from fertilizer under the PMT allocation (Table 4, column 6) ${ }^{21}$

Overall, the results in Table 4 and Figure 2 are consistent with chiefs taking productive efficiency into consideration when allocating input subsidies - something that the PMT cannot do since information on who has more to gain from fertilizer use is not something that can be elicited in an incentive-compatible way if people expect their subsidy package to depend on it. The magnitude of the effects is not trivial: a household with an extra log point gain from fertilizer gets about 6.5 more kgs of input subsidies under the chiefs than under the PMT.

Chiefs appear to have substantial power to enforce redistribution (as evidenced by the fact that they control how subsidy packages are shared among villages). This redistributive power may be what allows chiefs to use the input subsidies as a growth instrument, bringing their village closer to the production possibility frontier, and then enforcing sharing of food after harvest. Interestingly, allocating input subsidies based on returns is not what they are asked to do. The official guidelines of the inputs subsidy program is to target the poor, and thus when asked chiefs report targeting the poor rather than taking productivity into account (see Table A3) - even though our careful analysis of their allocation decision suggests that they do.

\footnotetext{
${ }^{21}$ The analysis in Table 4 only controls for $\log$ farm size, $\log$ PCF, and relation to chief in this regression: we omit other household controls such as demographics, since these controls themselves are predictors of log gains as shown in Table A8. Including all other controls attenuates coefficients (see Table A9), causing the relationship between yield increases and the value of the input subsidy to lose significance at conventional levels $(p=0.16)$. However, the gap in coefficients on log gains between the chief and conterfactual PMT allocation remains large, and for our primary outcome - the value gap between the fertilizer and food subsidies, the object of the model's prediction - the coefficient on log gains remains large and significant at $5 \%$ for the chief's allocation and small and insignificant under the PMT.
} 


\subsection{Supportive evidence}

Is information on the relative productivity of various potential beneficiaries of the input subsidy embedded in the chief, or does it rest in the people themselves? People who have high value for the input subsidy could wait in line more, lobby more or protest more if they don't get the subsidy, such that the allocation of the chief ultimately favors them in a way that looks as if the chief was himself aware of the heterogeneity.

Disentangling whether the information rests in the chief or can be elicited in an incentivecompatible way from the people is interesting, since a PMT scheme could possibly achieve some level of productive efficiency if the lobbying made to the chief was made to the outside government agent coming to the village to distribute the subsidy vouchers based on the PMT.

Yet the outside government agent would not be able to know the level of redistribution in the village; that is, she would not be able to gauge the "poverty mistargeting" cost of responding to the lobbying and targeting based on productive efficiency.

To provide descriptive evidence on this question, in the 2014 survey, we asked respondents if they had ever lobbied the chief to obtain subsidies. Only nine percent of respondents reported lobbying for input subsidies, and $4 \%$ reported lobbying for food subsidies (Table A3). The likelihood of having lobbied is not positively correlated with returns to fertilizer, however (see Table 4, column 7). In the survey of chiefs also conducted in 2014, we asked chiefs a number of questions about what they could observe about households, which we present in Appendix Table A10. We find that $86 \%$ of chiefs report that they can easily categorize farms in their villag in terms of productivity of inputs. Chiefs also report that they know who works harder, who has money for inputs, and whose returns are highest. While descriptive, these responses suggest significant local knowledge on the part of chiefs.

\section{Conclusion}

Traditional leaders, often known as "chiefs," have maintained a significant amount of de facto if not de jure power in sub-Saharan Africa. Possibly owing to the weakness of local governance in most of the continent, chiefs are commonly involved in the decisions of how to allocate government resources. One prominent type of resource is subsidies. Developing country governments allocate an important portion of their national budget to subsidies targeted at the poor, and it is common for chiefs to be asked to identify who should be eligible for such subsidies. Do chiefs identify the right beneficiaries? Previous work on this question concluded that there was widespread elite capture (Dorward et al., 2008; Kilic et al., 2013). These conclusions are based on evidence that "connected" households are more likely 
to receive subsidies, and that household assets measures do not strongly predict subsidy receipt. We show that such evidence may not directly speak to the issue of poverty-targeting in environments where assets are a poor predictor of need, and where the subsidized items are productive inputs.

Using detailed food expenditure and shocks data to better proxy for neediness, we show that since chiefs' kin are no better off than non-kin, the nepotism that is evident in the data does not imply greater poverty mistargeting. Chiefs do make more errors than a perfectly implemented PMT scheme would, but the gap reduces over time as the information used for the PMT becomes less accurate due to frequent shocks, while chiefs appear able to target based on such shocks.

Importantly, chiefs also appear to allocate input subsidies to farmers with larger returns to input use. This result underscores how a naive measure of targeting based solely on the neediness of households (even when needinesss is well measured) may understate the poverty-alleviation impacts of the allocation: when ex post redistribution is possible through informal transfers as in the context considered, targeting input subsidies based on productive efficiency (i.e. using input subsidies as a growth instrument) can have a larger if indirect impact on welfare than poverty-targeting. While this result is for one particular subsidy program in Malawi, the results have important policy implications because most of the inputs subsidized by governments are productive inputs (farming inputs, health inputs) that have heterogeneous returns. 


\section{References}

[1] Acemoglu, Daron, Tristan Reed and James A. Robinson (2014). "Chiefs - Economic Development and Elite Control of Civil Society in Sierra Leone." Journal of Political Economy 122 (2): 319-368.

[2] Alatas, Vivi, Abhijit Banerjee, Rema Hanna, Benjamin A. Olken, Ririn Purnamasari, and Matthew Wai-Poi (2013). "Does Elite Capture Matter? Local Elites and Targeted Welfare Programs in Indonesia." NBER Working Paper \#18798.

[3] Alatas, Vivi, Abhijit Banerjee, Rema Hanna, Benjamin A. Olken, and Julia Tobias (2012). "Targeting the Poor: Evidence from a Field Experiment in Indonesia." American Economic Review, 104 (2):1206-1240.

[4] Anderson, Siwan, Patrick Francois, and Ashok Kotwal (2015). "Clientelism in Indian villages." American Economic Review 105 (6): 1780-1816.

[5] Baltzer, Kenneth Thomas, and Henrik Hansen (2011). Agricultural input subsidies in sub-Saharan Africa. Ministry of Foreign Affairs of Denmark.

[6] Bardhan, Pranab (2002). "Decentralization of Governance and Development." Journal of Economic Perspectives, 16(4): 185-205.

[7] Bardhan, Pranab and Dilip Mookherjee (2000). "Capture and Governance at Local and National Levels." American Economic Review 90 (2): 135-139.

[8] Bardhan, Pranab and Dilip Mookherjee (2005). "Decentralizing antipoverty program delivery in developing countries." Journal of Public Economics 89: 675-704.

[9] Bardhan, Pranab and Dilip Mookherjee (2006). "Pro-poor targeting and accountability of local governments in West Bengal." Journal of Development Economics 79: 303-327.

[10] Beegle, Kathleen, Emanuela Galasso and Jessica Goldberg (2015). "Direct and Indirect Effects of Malawi's Public Works Program on Food Security." Mimeo, University of Maryland.

[11] Besley, Timothy J. (1990). "Means Testing versus Universal Provision in Poverty Alleviation Programmes." Economica 57 (225): 119-29.

[12] Cammack, Diana, Edge Kanyongolo, and Tam O’Neil (2009). 'Town Chiefs' in Malawi.' Africa Power and Politics Series. London, UK: Africa Power and Politics Programme, Overseas Development Institute.

[13] Chasuka, Michael, Chiweza, Asiyati, and Mercy Chikapa-Jamali (2014) "Public Participation in Local Councils in Malawi in the Absence of Local Elected Representatives- 
Political Eliticism or Pluralism?" Journal of Asian and African Studies Vol. 49(6) $705-720$.

[14] Chirwa, E., Matita, M., Dorward, A. (2010)." Factors Influencing Access to Agricultural Input Subsidy Coupons in Malawi." Future Agricultures Consortium, Brighton, Sussex

[15] Chirwa, Ephraim and Andrew Dorward (2013) Agricultural Input Subsidies. The Recent Malawi Experience. Oxford, Oxford University Press.

[16] Chirwa, Wiseman Chijere (2014) "Malawi Democracy and Political Participation" Open Society Initiative for Southern Africa.

[17] Coady, David; Grosh, Margaret; Hoddinott, John (2004). Targeting of transfers in developing countries : Review of lessons and experience. Washington, DC: World Bank.

[18] Cohen, Jessica, and Pascaline Dupas (2010). "Free Distribution or Cost-Sharing? Evidence from a Randomized Malaria Prevention Experiment." Quarterly Journal of Economics 125 (1): 1-45.

[19] Deaton, Angus (1997). The analysis of household surveys: a microeconometric approach to development policy. World Bank Publications.

[20] Deaton, Angus, and Salman Zaidi (2002). Guidelines for constructing consumption aggregates for welfare analysis. Vol. 135. World Bank Publications.

[21] Dizon-Ross, Rebecca, Pascaline Dupas and Jonathan Robinson (2016). "Governance and the Effectiveness of Public Health Subsidies: Evidence from Ghana, Kenya and Uganda." Unpublished.

[22] Dorward, A., E. Chirwa, V. Kelly, T.S. Jayne, R. Slater, and D. Boughton. (2008). "Evaluation of the 2006/07 Agricultural Input Subsidy Programme, Malawi." Final Report. London, England: School of Oriental and African Studies

[23] Dorward A, Chirwa E., Matita M., Mhango W., Mvula P., Taylor E. and K. Thorne (2013). "Evaluation of the 2012/13 farm input subsidy programme, Malawi."

[24] Dupas, Pascaline, Dean Karlan, Jonathan Robinson, and Diego Ubfal (2017a). "Banking the Unbanked? Evidence from three countries." NBER Working Paper No. 22463.

[25] Dupas, Pascaline, Anthony Keats, and Jonathan Robinson (2017b). "The Effect of Savings Accounts on Interpersonal Financial Relationships: Evidence from a Field Experiment in Rural Kenya" NBER Working Paper No. 21339. 
[26] Eggen, Øyvind (2011). "Chiefs and everyday governance: Parallel state organisations in Malawi." Journal of Southern African Studies 37 (2): 313-331.

[27] Galasso, Emanuela, and Martin Ravallion (2005). "Decentralized targeting of an antipoverty program". Journal of Public Economics 89: 705-727.

[28] Hussein, Mustafa Kennedy (2005). Good governance and the new local government system in Malawi: challenges and prospects. Doctoral dissertation, University of Johannesburg.

[29] Kilic, Talip, Edward Whitney and Paul Winters (2013) "Decentralized Beneficiary Targeting in Large-Scale Development Programs: Insights from the Malawi Farm Input Subsidy Program." Policy Research Working Paper 6713. World Bank.

[30] Ligon, Ethan (2015). "Estimating Household Neediness from Disaggregate Expenditures." CUDARE working paper.

[31] Lihoma, Paul (2012). The impact of administrative change on record keeping in Malawi. Doctoral dissertation, University of Glasgow.

[32] Logan, Carolyn (2011). "The roots of resilience: Exploring popular support for African Traditional Authorities". Afrobarometer Working Paper No. 128.

[33] Malawi Government (1998) Local Government Act.

[34] Malawi Ministry of Agriculture and Food Security (MoAFS) (2009). "2009-2010 farm input subsidy program implementation guidelines." Lilongwe: MoAFS

[35] Meyer, Bruce and James Sullivan (2012). "Identifying the Disadvantaged: Official Poverty, Consumption Poverty, and the New Supplemental Poverty Measure." Journal of Economic Perspectives 26 (3): 111-135.

[36] Michalopoulos, Stelios, and Elias Papaioannou (2013). "Pre-Colonial Ethnic Institutions and Contemporary African Development." Econometrica 81 (1): 113-152.

[37] Niehaus, Paul, Antonia Attanassova, Mariane Bertrand and Sendhil Mullainathan (2013). "Targeting with Agents." American Economic Journal: Economic Policy 5 (1): 206-238.

[38] Olken, Benjamin A. (2005). "Revealed Community Equivalence Scales." Journal of Public Economics, 89 (2-3): 545-566.

[39] Patel, Nandini, Richard Tambulasi, Bright Molande and Andrew Mpesi (2007). "Consolidating Democratic Governance in southern Africa: Malawi". EISA REsearch Report No. 33. EISA, Johannesburg, South Africa. 
[40] Peters, Pauline (2010). Our daughters inherit our land, but our sons use their wives' fields": matrilineal-matrilocal land tenure and the New Land Policy in Malawi. Journal of Eastern African Studies, 4:1, 179-199.

[41] Reserve Bank of Malawi (RBM) (2012) Financial and Economic Review. Reserve Bank of Malawi, volume 44, number 2.

[42] Reserve Bank of Malawi (RBM) (2014) Financial and Economic Review. Reserve Bank of Malawi, volume 46, number 2.

[43] Stoeffler, Quentin, Bradford Mills, and Carlo Del Ninno (2016). "Reaching the Poor: Cash Transfer Program Targeting in Cameroon." World Development 83: 244-263.

[44] Strauss, John (1986). "Does better nutrition raise farm productivity?" Journal of Political Economy 94 (2): 297-320.

[45] USAID (2012) Inadequate funding for humanitarian assistance programs could result in Crisis and Emergency-level food security outcomes in 2012/13. Malawi Food Security Outlook.

[46] World Bank (2015). Development Indicators Database. Accessed February 26, 2015. http://data.worldbank.org/indicator

[47] Wiggins, Steve and Jonathan Brooks (2010. "The Use of Input Subsidies in Developing Countries." OECD working paper. 
Table 1. Summary Statistics on Households in the sample

\begin{tabular}{|c|c|c|c|c|c|c|}
\hline \multirow[b]{3}{*}{$\underline{\text { Panel A. Time-Invariant Baseline Variables }}$} & $(1)$ & $(2)$ & $(3)$ & $(4)$ & $(5)$ & (6) \\
\hline & \multirow{2}{*}{$\begin{array}{l}\text { Overall } \\
\text { Mean }\end{array}$} & \multirow{2}{*}{$\begin{array}{l}\text { Std. } \\
\text { Dev. }\end{array}$} & \multicolumn{2}{|c|}{$\begin{array}{c}\text { Difference } \\
\text { kin vs. non-kin }\end{array}$} & \multirow{2}{*}{$\begin{array}{l}\text { Correlation } \\
\text { between } \\
\text { rounds } \\
\text { (all) }\end{array}$} & \multirow{2}{*}{$\begin{array}{c}\text { Correlation } \\
\text { between } \\
\text { rounds } \\
\text { (kin only) } \\
\end{array}$} \\
\hline & & & Diff. & $\begin{array}{l}\text { Std. } \\
\text { Err. }\end{array}$ & & \\
\hline Related to chief ("Kin") & 0.27 & - & & & & \\
\hline Mud/dirt floor & 0.90 & - & 0.02 & 0.02 & & \\
\hline Thatch roof & 0.77 & - & 0.01 & 0.02 & & \\
\hline Has electricity in dwelling & 0.006 & - & 0.002 & 0.004 & & \\
\hline Reads or writes chichewa & 0.58 & - & -0.07 & $0.029^{*}$ & & \\
\hline Years of education & 4.86 & 3.54 & -0.50 & $0.205^{*}$ & & \\
\hline Widowed or divorced female & 0.29 & - & 0.03 & 0.03 & & \\
\hline Owns land & 0.97 & - & 0.03 & $0.01^{*}$ & & \\
\hline Household size & 4.57 & 2.07 & -0.06 & 0.12 & & \\
\hline Number of children & 2.49 & 1.72 & -0.06 & 0.10 & & \\
\hline Respondent age & 40.14 & 17.09 & 0.50 & 0.99 & & \\
\hline If yes, acres of land owned & 2.36 & 1.96 & 0.19 & 0.11 & & \\
\hline Value of durable assets owned (USD) & 98.04 & 384.06 & -11.27 & 22.32 & & \\
\hline Value of animals owned (USD) & 36.76 & 105.51 & -2.43 & 6.15 & & \\
\hline Number of households & 1559 & & & & & \\
\hline \multicolumn{7}{|l|}{$\underline{\text { Panel B. Time-varying Variables }}$} \\
\hline Total expenditures per capita (monthly) ${ }^{1}$ & 9.66 & 10.85 & -0.476 & 0.313 & 0.45 & 0.43 \\
\hline Total food expenditures per capita (monthly eq.) & 6.80 & 7.77 & -0.349 & 0.224 & 0.35 & 0.35 \\
\hline PCF: Total non-staple food expenditures per capita (monthly eq) & 2.71 & 3.45 & -0.186 & $0.099^{* *}$ & 0.38 & 0.35 \\
\hline \multicolumn{7}{|l|}{ Shocks } \\
\hline Experienced drought or flood (past 3 months) & 0.28 & - & 0.005 & 0.013 & -0.33 & -0.33 \\
\hline Experienced cattle death or crop disease (past 3 months) & 0.20 & - & 0.013 & 0.012 & 0.04 & 0.06 \\
\hline Respondent missed work due to illness (past month) & 0.26 & - & -0.002 & 0.015 & 0.16 & 0.11 \\
\hline Other household member was sick (past month) & 0.69 & - & 0.007 & 0.013 & 0.16 & 0.18 \\
\hline Report being worried about having enough food to eat (past month) & 0.72 & - & -0.023 & 0.012 & 0.14 & 0.13 \\
\hline Share of days with enough food to eat & 0.67 & & 0.004 & 0.016 & 0.19 & 0.18 \\
\hline \multicolumn{7}{|l|}{ Informal redistribution } \\
\hline Received transfers from other villagers in past 90 days & 0.58 & & -0.017 & 0.014 & 0.11 & 0.14 \\
\hline Made transfers to other villagers in past 90 days & 0.25 & & -0.003 & 0.013 & 0.07 & 0.06 \\
\hline Number of observations & 6236 & & & & & \\
\hline Number of households & 1559 & & & & & \\
\hline \multicolumn{7}{|l|}{ Panel C. Reported returns to fertilizer (2014 Survey) } \\
\hline Self-reported total production without fertilizer use (50 kg bags) & 3.87 & 2.62 & 0.25 & 0.25 & & \\
\hline Self-reported total production with fertilizer use (50 kg bags) & 18.48 & 9.41 & 0.42 & 0.87 & & \\
\hline Gain in production from using fertilizer (50 kg bags) & 14.50 & 8.05 & 0.20 & 0.76 & & \\
\hline Gain in production from using fertilizer ( $50 \mathrm{~kg}$ bags), per acre & 7.83 & 4.92 & 0.20 & 0.47 & & \\
\hline Number of households & 532 & & & & & \\
\hline
\end{tabular}

Note: All monetary amounts are in US dollars. Years of education is highest in the household (husband or wife).

${ }^{1}$ Expenditures are winsorized at the 99th percentile. 
(1)

2011 Input Subsidy

2012 Input Subsidy

$\begin{array}{ll}0.753 & 0.812 \\ 0.000 & 0.000 \\ 0.098 & 0.148\end{array}$

000

0.148

$(3)$

Percentage of population receiving subsidy

Percentage of villages in which $0 \%$ received subsidy

Percentage of villages in which $100 \%$ received

If between 0 and 100\%

Simple error rate under following allocation mechanism: ${ }^{1}$

$$
\begin{aligned}
& \text { Chief (True allocation) } \\
& \text { PMT (Counterfactual) } \\
& \text { PMT (Counterfactual) based on } \\
& \text { Random (Counterfactual) } \\
& P \text {-val Chiefs }=P M T \\
& P \text {-val Chiefs }=P M T \text { (IHS3) } \\
& P \text {-val Chiefs }=\text { Random } \\
& P \text {-val PMT }=\text { Random }
\end{aligned}
$$$$
\text { PMT (Counterfactual) based on IHS3 formula }
$$

Mean squared error in $\log$ consumption under following allocation mechanism: ${ }^{2}$

$\begin{array}{llll}\text { Chief (True allocation) } & 0.497 & 0.269 & 0.375 \\ \text { PMT (Counterfactual) } & 0.199 & 0.126 & 0.193 \\ \text { PMT (Counterfactual) based on IHS3 formula } & 0.282 & 0.154 & 0.250 \\ \text { Random (Counterfactual) } & 0.543 & 0.808 & 1.084 \\ P \text {-val Chiefs }=P M T & <.001 & 0.005 & 0.057 \\ P \text {-val Chiefs }=P M T \text { (IHS3) } & 0.439 & <.001 & <.001 \\ P \text {-val Chiefs }=\text { Random } & <.001 & <.001 & <.001 \\ P \text {-val PMT }=\text { Random } & <.001 & <.001 & <.001\end{array}$
Notes: IHS 3 = Malawi Third Integrated Household Survey, a representative survey conducted by Malawi's National Statistical Office from March 2010 to March 2011.

${ }^{1}$ Error rate is defined as the percentage of people who received the subsidy and shouldn't have. Since the total number of beneficiaries is fixed, this error rate is equal to the percentage of people who didn't receive the subsidy and should have.

${ }^{2}$ Mean squared error is calculated as deviations from the log PCF threshold.

$\begin{array}{ll}0.140 & 0.151 \\ 0.104 & 0.141 \\ 0.116 & 0.145 \\ 0.126 & 0.162 \\ 0.003 & 0.365 \\ 0.031 & 0.585 \\ 0.229 & 0.275 \\ <.001 & <.001\end{array}$

0.375

0.250

1.084

$<.001$

$<.001$

$<.001$

0.002

.001

0.461 


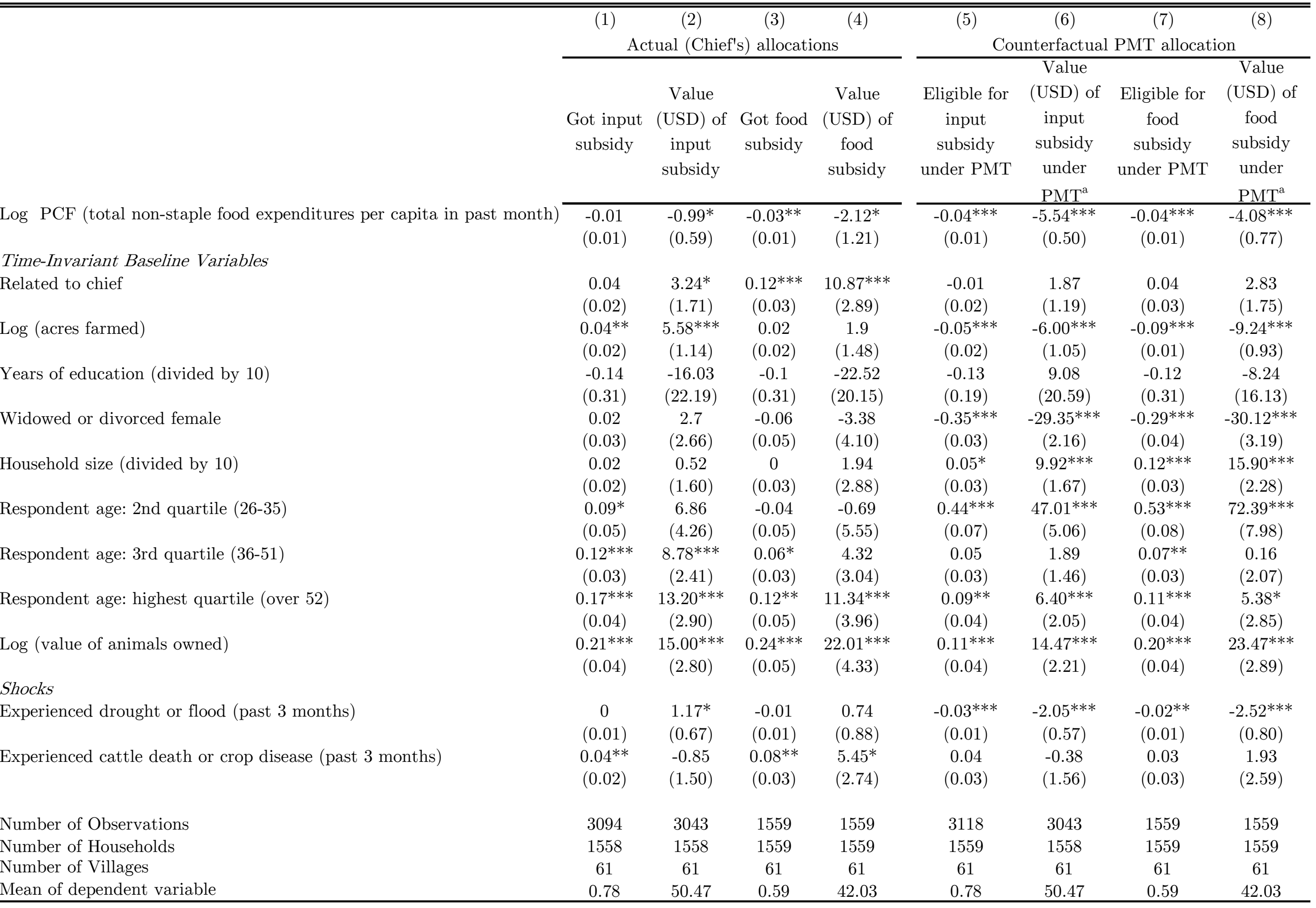

Note: Regressions for input subsidies pool years 2011 and 2012 and control for the year. Omitted age category is less than 26. Standard errors clustered at the village level. All regressions include village fixed effects.

${ }^{a}$ Counterfactual quantities have the same distribution as actual quantities.

* significant at $10 \%$;* significant at $5 \%$; ** significant at $1 \%$ 


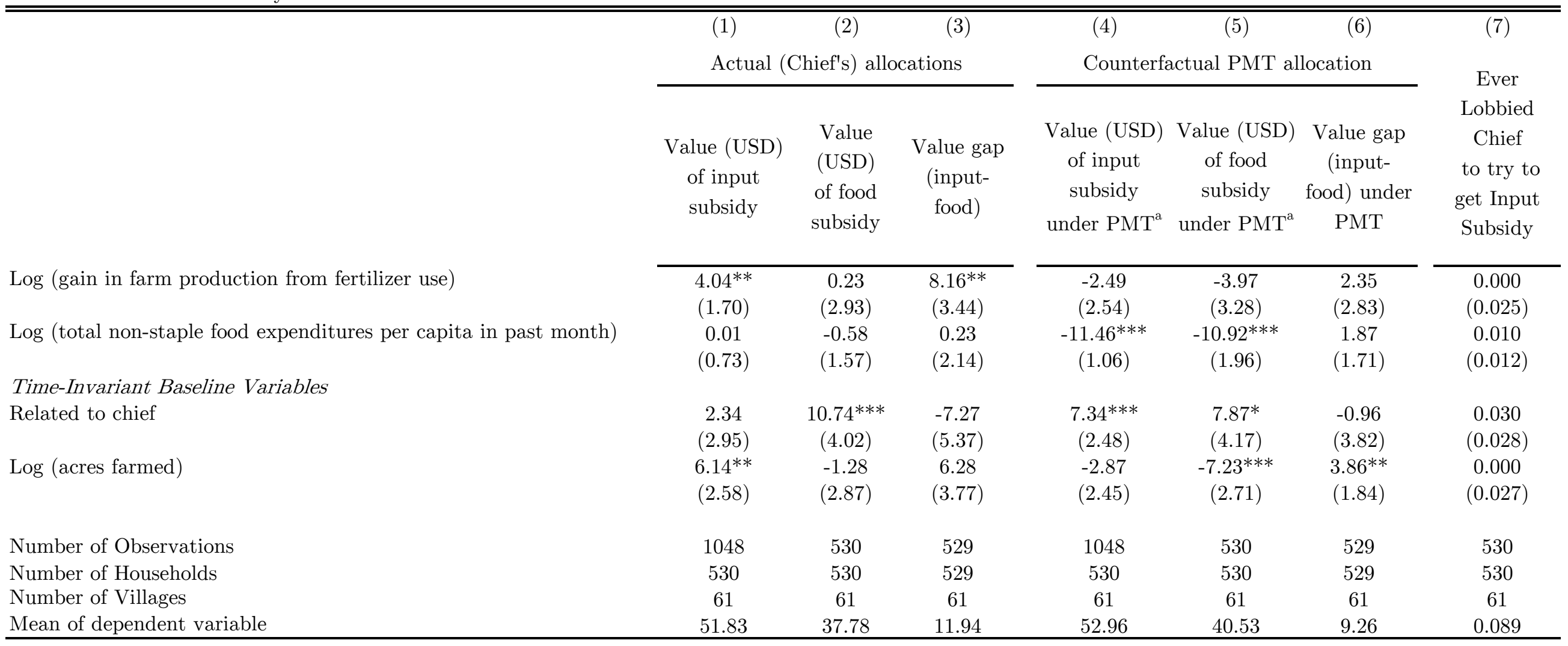

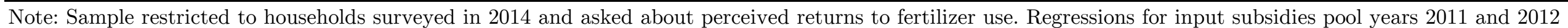

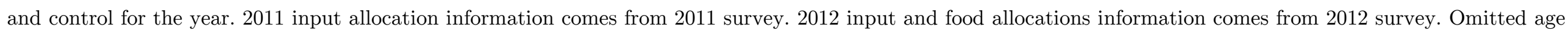
category is less than 26. Standard errors clustered at the village level. All regressions control for village fixed effects.

$*$ significant at $10 \% ; * *$ significant at $5 \% ; * * *$ significant at $1 \%$ 

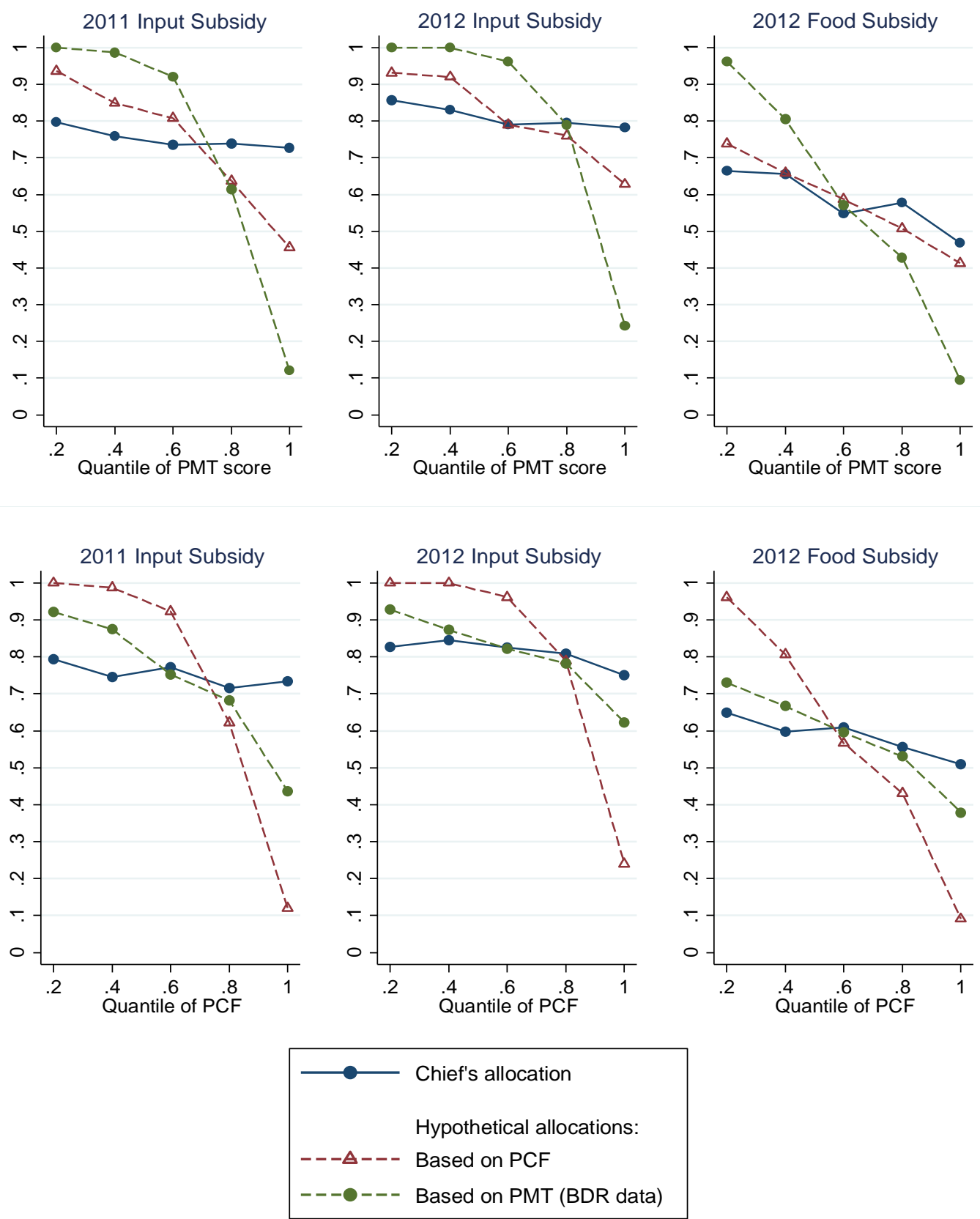

Notes: See main text section 4.2. The PMT formula is obtained using 2011 data. The PCF is contemporaneous of the subsidy allocation decision. The chief allocation is the allocation observed, made by chiefs. Because the share of households that receive subsidies vary across villages, the threshold PMT (PCF) score for eligibility varies across villages, which explains why the allocations by PMT (PCF) quantile are not either 1 or 0 . 


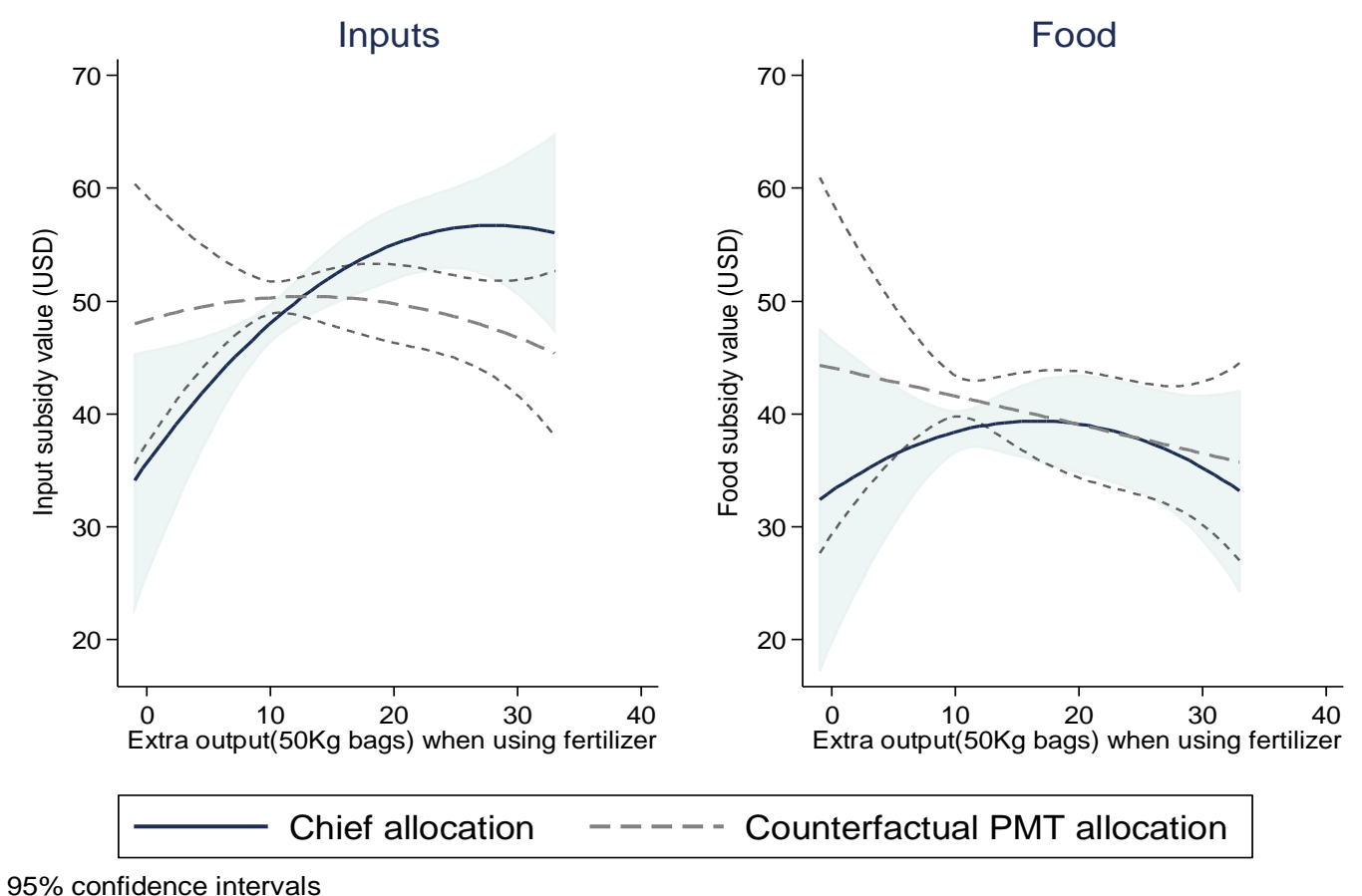

Notes: 2012 data. Estimates from OLS regressions with second-order polynomial in the variable shown on the $\mathrm{x}$-axis as well as controls for PCF, log land size, and chief kinship. 


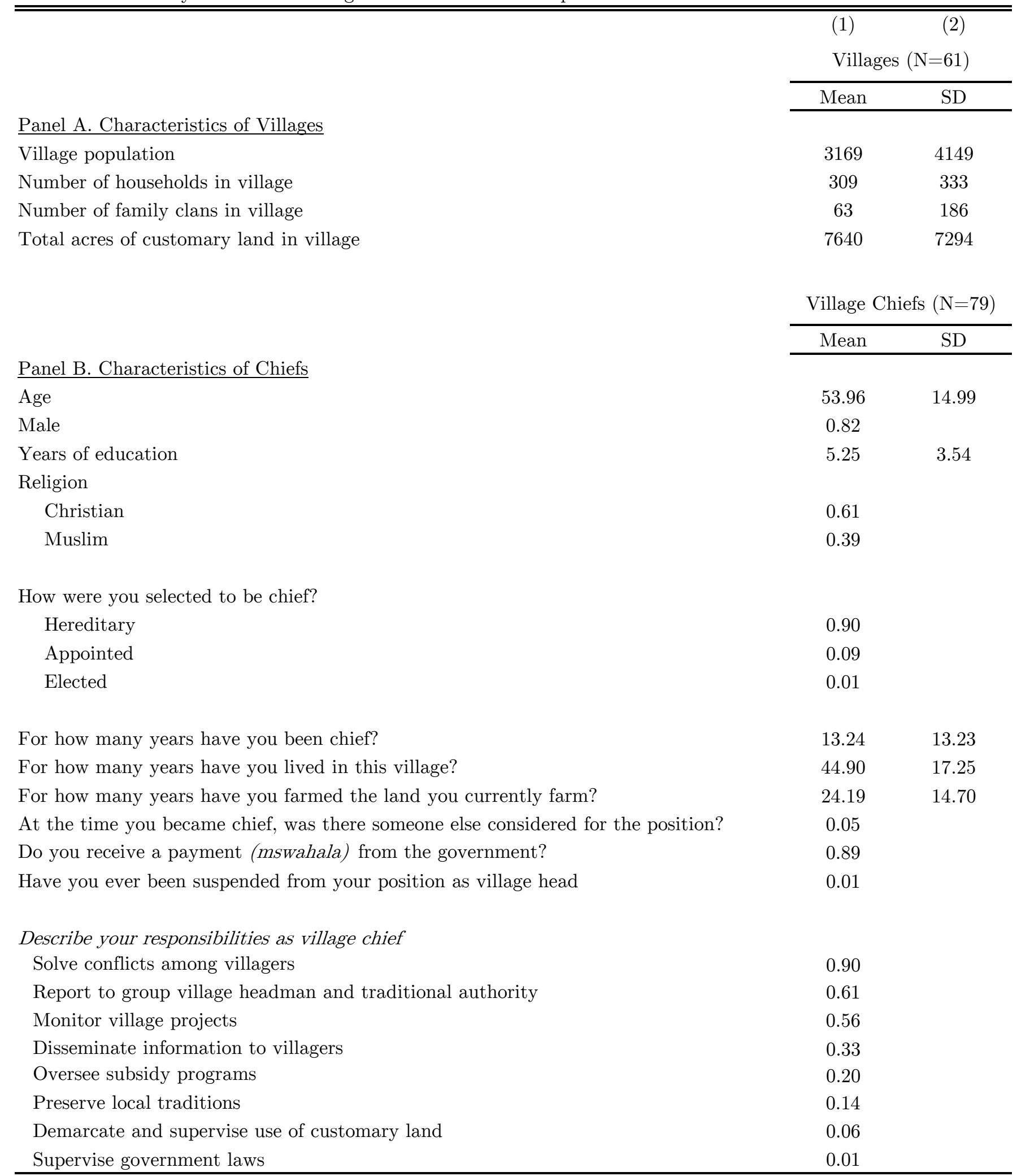

Notes: Data from surveys conducted from August to October 2014 in the study districts. 
Panel A. Surveys of Chiefs in $2014(\mathrm{~N}=79)$

Who decides which households in the village will be beneficiaries of the subsidy program?

Village head (chief) alone

0.62

Village Development Committee alone

0.13

Village meeting

0.13

District agricultural officer alone

0.06

Group village head alone

0.04

Chief in consult with others

0.03

What selection criteria are used to allocate vouchers in your village? (multiple answers possible)

Neediness

Absence of male head

Recent negative shocks

Child headed households and households taking care of orphans

How hard-working the household is

Farm size

$\underline{\text { Panel B. Survey of villagers in } 2013(\mathrm{~N}=1,381)}$

The chief organized a meeting to talk about the program

If yes, did you attend the meeting?

At the meeting, was there a discussion about:

Who should be included in the program?

$\underline{\text { Panel C. Survey of villagers in } 2014(\mathrm{~N}=542)}$

Who decides which households in the village will be beneficiaries of the subsidy program?

Village head (chief) alone

Other

What selection criteria are used to allocate vouchers in your village?

Neediness

Elderly, disabled, or chronically ill

Child headed households and households taking care of orphans

Absence of male head

Recent negative shocks

How hard-working the household is

Farm size

Households with more children

Households with poor land

Households not receiving other subsidies

Do you think the subsidy is allocated in a good way?

Very good

Somewhat good

Not so good

Very bad

What is your definition of a "good" allocation? An allocation that...

$0.02 \quad 0.01$

... benefits the poorest

... increases total village production so that there is more food to share

... rewards those who work hard

... provides at least something to most households

0.07

0.03

0.37 
$\underline{\text { Panel A. Input subsidy }}$

Received input subsidy in 2008

0.58

..................................in 2009

0.66

in 2010

0.73

in 2011

0.75

in 2012

0.81

If any, kgs of fertilizer received in 2011

81.58

26.54

64.22

25.47

If any, $\mathrm{kgs}$ of seeds received in 2011

If received subsidy, value of 2011 package ${ }^{1}$

72.28

Received input subsidy all 5 years

Never received input subsidy

Sharing (based on 2014 villagers survey, $N=504$ )

Received voucher and didn't share

Received voucher and shared

Received share of someone's voucher

Didn't receive a voucher or share

Who decided the voucher would be shared? (Asked of voucher recipients)

Village Chief

Villagers themselves

Other

Who decided with whom the voucher would be shared? (Asked of voucher recipients)

Village Chief

Villagers themselves

Other

Who decided with whom the voucher would be shared? (Asked of share recipients)

Village Chief

Villagers themselves

Other

$\underline{\text { Panel B. Food Subsidy }}$

Received food subsidy in 2012

If received subsidy, value of package

72.00

37.40

Received both food and input subsidy in 2012

0.53

Sharing (based on 2014 villagers survey, $N=504$ )

Who decided with whom the food would be shared?

Village Chief

Group Village Chief

0.03

Villagers themselves

0.13

Other

0.09

Note: All monetary amounts are in US dollars. Exchange rate was roughly $150 \mathrm{MWK}$ to $\$ 1$ at the time of the baseline, and it was 300 MWK to $\$ 1$ in late 2012 . 
Table TA4. PMT formula

\begin{tabular}{|c|c|c|}
\hline & (1) & $(2)$ \\
\hline & $\log \mathrm{PCF}$ & $\log \mathrm{PAEF}$ \\
\hline Household size (divided by 10 ) & $\begin{array}{c}-4.73^{* * *} \\
(0.74)\end{array}$ & $\begin{array}{c}-3.04^{* * *} \\
(0.55)\end{array}$ \\
\hline Household size (divided by 10) squared & $\begin{array}{c}1.91^{* * *} \\
(0.48)\end{array}$ & $\begin{array}{c}1.22^{* * *} \\
(0.42)\end{array}$ \\
\hline Number of children under 5 (divided by 10 ) & - & $\begin{array}{c}1.23^{* * *} \\
(0.34)\end{array}$ \\
\hline Total number of children (divided by 10 ) & $\begin{array}{l}0.54^{*} \\
(0.32)\end{array}$ & - \\
\hline Log durable assets & $\begin{array}{c}0.40^{* * *} \\
(0.03)\end{array}$ & $\begin{array}{c}0.40^{* * *} \\
(0.03)\end{array}$ \\
\hline Log animal assets & - & - \\
\hline Owns land & - & - \\
\hline Owns land $*$ log acres owned & $\begin{array}{c}0.10^{* *} \\
(0.04)\end{array}$ & $\begin{array}{c}0.09^{* *} \\
(0.04)\end{array}$ \\
\hline Widowed or Divorced Female Head & $\begin{array}{c}-0.27^{* * *} \\
(0.07)\end{array}$ & - \\
\hline Age of respondent (divided by 100) & - & - \\
\hline Age of respondent (divided by 100) squared & $\begin{array}{c}-1.28^{* * *} \\
(0.28)\end{array}$ & $\begin{array}{c}-1.30^{* * *} \\
(0.27)\end{array}$ \\
\hline Highest education within household & $\begin{array}{c}0.05^{* * *} \\
(0.01)\end{array}$ & $\begin{array}{c}0.06^{* * *} \\
(0.01)\end{array}$ \\
\hline Household head is literate & - & - \\
\hline Home has mud or dirt floors & $\begin{array}{c}-0.16^{*} \\
(0.10)\end{array}$ & - \\
\hline Home has thatch roof & - & - \\
\hline Home has mud or dirt walls & - & - \\
\hline Toilet is private covered latrine & - & - \\
\hline Toilet is uncovered latrine & - & - \\
\hline No toilet & - & - \\
\hline Water source is public tap & $\begin{array}{c}0.69 * * * \\
(0.19)\end{array}$ & $\begin{array}{c}0.64^{* * *} \\
(0.20)\end{array}$ \\
\hline Water source is well & $\begin{array}{c}0.58^{* * *} \\
(0.19)\end{array}$ & $\begin{array}{c}0.55^{* *} \\
(0.21)\end{array}$ \\
\hline Water source is piped water & $\begin{array}{c}1.02^{* * *} \\
(0.32)\end{array}$ & $\begin{array}{c}1.05^{* * *} \\
(0.30)\end{array}$ \\
\hline Has electricity & - & - \\
\hline Has a mobile phone & - & - \\
\hline Main occupation $=$ vendor & - & - \\
\hline Main occupation $=$ owner of other business & - & - \\
\hline R-squared & 0.32 & 0.28 \\
\hline Households & 1559 & 1559 \\
\hline Villages & 61 & 61 \\
\hline
\end{tabular}

Notes: Baseline data. PC(PAE)F = per capita (per adult eq) expenditures on non-staple food (monthly eq.), in USD. Sequential selection of variables done using Stata backward stepwise regression. Standard errors, clustered by village, in parentheses. ${ }^{*}, * *$, and ${ }^{* * *}$ denote significance at $10 \%, 5 \%$, and $1 \%$. 
Household size (divided by 10)

BDR variables only All IHS3 Variables

Household size (divided by 10) squared

$\begin{array}{cc}-5.82^{* * *} & -5.63^{* * *} \\ (0.66) & (0.68) \\ 2.66^{* * *} & 2.58^{* * *} \\ (0.56) & (0.57) \\ -1.24^{* * *} & -1.16^{* * *} \\ (0.39) & (0.42) \\ 1.01^{* *} & 0.84^{*} \\ (0.42) & (0.46) \\ 0.17^{* * *} & 0.17^{* * *} \\ (0.03) & (0.03)\end{array}$

Log animal assets

Owns land

$-0.18^{*}$

Owns land $* \log$ acres owned

Widowed or Divorced Female Head

$-0.26^{* * *}$

(0.09)

$-0.24^{* * *}$

Age of respondent (divided by 100)

$-$

Age of respondent (divided by 100) squared

$-0.38^{* *}$

$-0.40^{* *}$

(0.18)

(0.18)

Highest education within household

$0.03^{* *}$

$0.03^{* *}$

(0.01)

(0.01)

Household head is literate

Home has mud or dirt floors

Home has thatch roof

Home has mud or dirt walls

Toilet is private covered latrine

Toilet is uncovered latrine

$(0.12)$

$-0.30^{*}$

(0.16)

$0.48^{* * *}$

$(0.12)$

$0.48^{* * *}$

Water source is public tap

-

Water source is well

Water source is piped water

Has electricity

$0.35^{*}$

(0.18)

Has a mobile phone

Main occupation $=$ vendor

Main occupation $=$ owner of other business

Variables in IHS3 but not BDR

Value of house (USD)

Has trash pit for garbage

R-squared

Households

Villages

Notes: Data comes from Malawi Integrated Household Survey Wave 3 (IHS3). PCF = per capita (per adult eq) expenditures on non-staple food (monthly eq.), in USD. Sequential selection of variables done

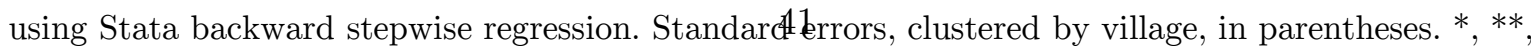




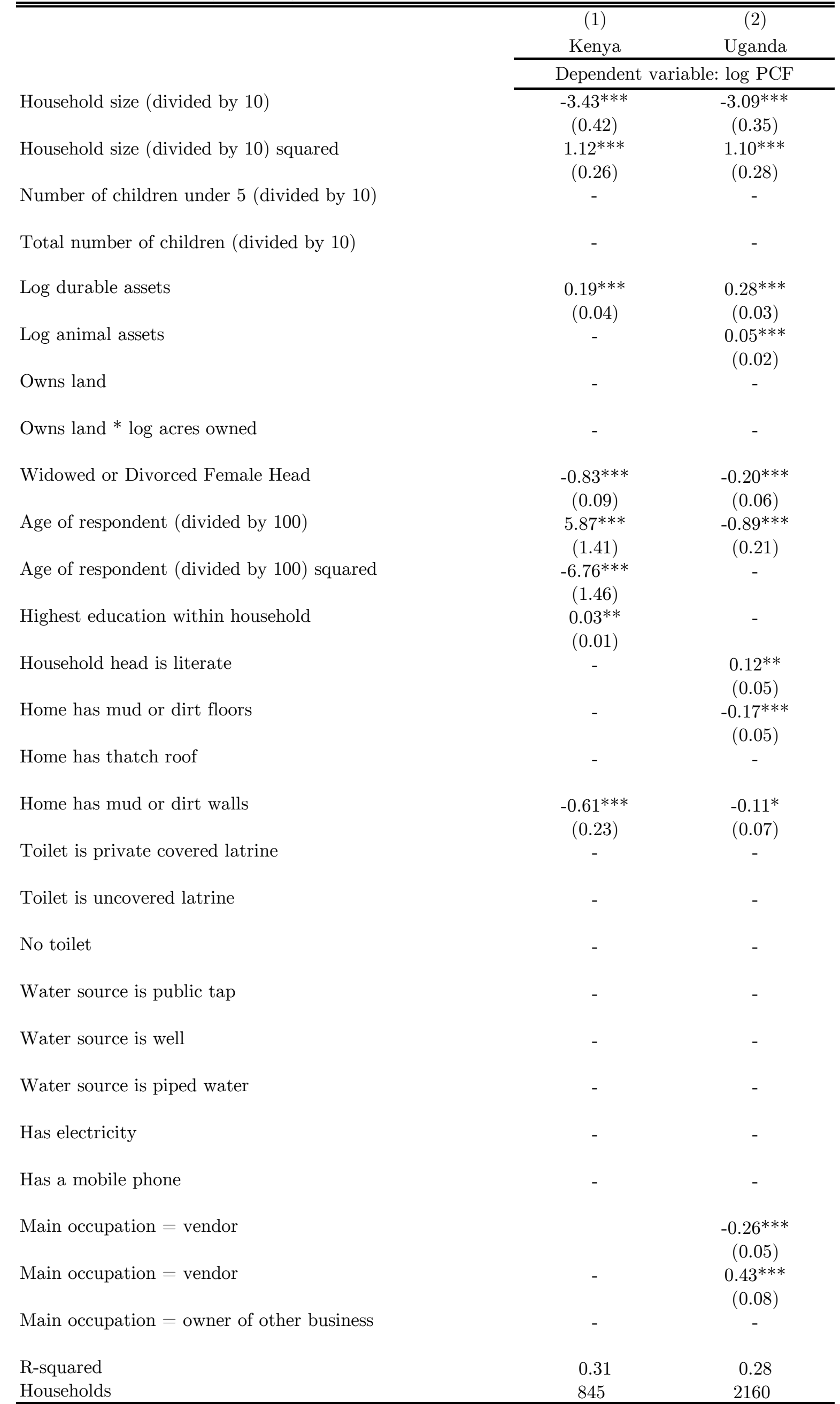

Notes: Data from surveys conducted in 2010 in Kenya (Dupas, Keats and Robinson 2016) and Uganda (Dupas et al. 2016). Dependent variable is total household log per capita food expenditures. $* * *$, and $* * *$ denote significance $\$ 210 \%, 5 \%$, and $1 \%$. 


\begin{tabular}{|c|c|c|c|c|c|}
\hline & $(1)$ & $(2)$ & $(3)$ & (4) & $(5)$ \\
\hline & $\begin{array}{l}\text { Log (total } \\
\text { expenditures per } \\
\text { capita) }\end{array}$ & $\begin{array}{l}\text { Log (total food } \\
\text { expenditure per } \\
\text { capita) }\end{array}$ & $\begin{array}{c}\text { Food share of } \\
\text { expenditures }\end{array}$ & $\begin{array}{c}\text { Percent of days } \\
\text { without enough food }\end{array}$ & $\begin{array}{c}\text { Dummy }=1 \text { if not } \\
\text { worried about having } \\
\text { enough food }\end{array}$ \\
\hline \multirow[t]{2}{*}{ Log PCF (non-staple food expenditures per capita) } & $0.62^{* * *}$ & $0.69^{* * *}$ & $0.02^{* * *}$ & $-0.04 * * *$ & $0.05^{* * *}$ \\
\hline & $(0.01)$ & $(0.02)$ & $(0.00)$ & $(0.00)$ & $(0.01)$ \\
\hline Observations & 6,027 & 6,027 & 6,027 & 6,018 & 4,507 \\
\hline Number of villages & 61 & 61 & 61 & 61 & 61 \\
\hline Number of households & 1,558 & 1,558 & 1,558 & 1,558 & 1,558 \\
\hline R-squared & 0.57 & 0.54 & 0.02 & 0.02 & 0.02 \\
\hline Mean of Dep. Var. & 1.78 & 1.35 & 0.70 & 0.28 & 0.33 \\
\hline
\end{tabular}

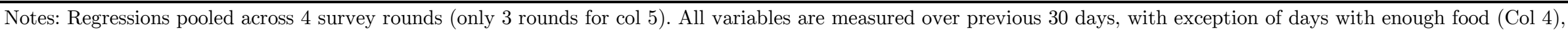
which was measured over 30 days in the first 2 surveys, and 90 days over the last 2 surveys. Standard errors in parentheses.

* significant at $10 \% ;{ }^{* *}$ significant at $5 \% ;{ }^{* * *}$ significant at $1 \%$ 
Dependent variable: Log (gain in farm production from fertilizer use)

$\log$ (acres farmed)

$0.13^{* * *}$

(0.04)

Related to chief

$-0.01$

(0.04)

Years of education (divided by 10)

$0.25 * * *$

(0.08)

0.00

(0.05)

$0.23 *$

$(0.12)$

$0.13^{* *}$

(0.06)

$0.21^{* * *}$

(0.06)

$0.22^{* * *}$

Respondent age: highest quartile (over 52)

$(0.08)$

Log (value of animals owned)

(0.02)

Number of Observations 530

Number of Villages

Mean of dependent variable

2.04

$\mathrm{SD}$ of dependent variables

0.74

$\mathrm{R}$-squared (no village $\mathrm{FE}$ )

0.14

Note: Omitted age category is less than 26. Standard errors clustered at the village level.

Regression includes village fixed effects.

* significant at $10 \%$; ** significant at 5\%; *** significant at $1 \%$ 


\begin{tabular}{ccc} 
Actual (Chief's) allocations \\
\hline & Value & Value gap \\
Value (USD) & (USD) & (input- \\
of input & of food & food) \\
subsidy & subsidy &
\end{tabular}

Counterfactual PMT allocation

Value (USD) Value (USD) Value gap of input of food (inputsubsidy under subsidy food) under $\mathrm{PMT}^{\mathrm{a}}$ under $\mathrm{PMT}^{\mathrm{a}} \quad \mathrm{PMT}$

\begin{tabular}{|c|c|c|c|}
\hline $\begin{array}{l}-2.75 \\
(1.86)\end{array}$ & $\begin{array}{l}-5.14^{*} \\
(2.87)\end{array}$ & $\begin{array}{l}2.82 \\
(2.91)\end{array}$ & $\begin{array}{c}0.000 \\
(0.026)\end{array}$ \\
\hline $\begin{array}{c}-5.67^{* * *} \\
(1.07)\end{array}$ & $\begin{array}{c}-4.33^{* * *} \\
(1.46)\end{array}$ & $\begin{array}{c}0.05 \\
(1.58)\end{array}$ & $\begin{array}{c}0.000 \\
(0.012)\end{array}$ \\
\hline $4.69 * *$ & $5.26^{*}$ & -0.3 & 0.040 \\
\hline$(2.29)$ & $(2.94)$ & $(3.55)$ & (0.031) \\
\hline $\begin{array}{c}-5.55^{* *} \\
(2.41)\end{array}$ & $\begin{array}{c}-9.40^{* * *} \\
(2.13)\end{array}$ & $\begin{array}{c}4.70^{* *} \\
(1.82)\end{array}$ & $\begin{array}{c}0.010 \\
(0.030)\end{array}$ \\
\hline $\begin{array}{c}-29.87^{* * *} \\
(4.18)\end{array}$ & $\begin{array}{c}-33.00^{* * *} \\
(4.96)\end{array}$ & $\begin{array}{c}7.88 \\
(4.90)\end{array}$ & $\begin{array}{c}0.010 \\
(0.060)\end{array}$ \\
\hline $\begin{array}{c}10.48^{* * *} \\
(2.53)\end{array}$ & $\begin{array}{c}16.76^{* * *} \\
(3.73)\end{array}$ & $\begin{array}{l}-5.01 \\
(3.87)\end{array}$ & $\begin{array}{c}0.000 \\
(0.033)\end{array}$ \\
\hline $49.30^{* * *}$ & $68.32^{* * *}$ & $-21.99 *$ & 0.020 \\
\hline$(9.11)$ & (13.56) & $(11.51)$ & $(0.078)$ \\
\hline 2.01 & -0.92 & 2.72 & $-0.10^{* *}$ \\
\hline$(3.43)$ & $(4.65)$ & $(4.43)$ & $(0.050)$ \\
\hline 4.95 & -0.69 & 4.4 & $-0.12^{*}$ \\
\hline$(3.66)$ & $(4.62)$ & (5.18) & $(0.064)$ \\
\hline $14.14^{* * *}$ & $13.14^{* *}$ & -0.55 & $-0.14^{* *}$ \\
\hline$(4.57)$ & $(5.75)$ & $(6.07)$ & $(0.064)$ \\
\hline
\end{tabular}

Log (value of animals owned)

\begin{tabular}{ccc}
\hline 2.33 & -0.84 & $7.57^{* *}$ \\
$(1.64)$ & $(2.52)$ & $(3.36)$ \\
1.03 & 1.94 & -1.36 \\
$(0.87)$ & $(1.89)$ & $(2.54)$
\end{tabular}

Time-Invariant Baseline Variables Related to chief

$\log$ (acres farmed)

Years of education (divided by 10)

Widowed or divorced female

Household size (divided by 10)

Respondent age: 2nd quartile (26-35)

Respondent age: 3rd quartile (36-51)

Respondent age: highest quartile (over 52)

Shocks

Experienced drought or flood (past 3 months)

Experienced cattle death or crop disease (past 3 months)

$\begin{array}{ccc}0.68 & 4.70 & -3.90 \\ (3.68) & (4.90) & (6.14) \\ 3.49 & -1.44 & 5.26 \\ (2.53) & (4.31) & (4.49)\end{array}$

$\begin{array}{ccc}0.79 & 0.04 & -0.08^{* *} \\ (4.73) & (4.78) & (0.029) \\ 5.02 & -3.24 & -0.02\end{array}$

-2.25
$(3.06)$
2.25
$(2.32)$

(3.09)

(3.11)

(0.021)

Number of Observations

Number of Households

Number of Villages

$\begin{array}{ccc}1048 & 530 & 529 \\ 530 & 530 & 529 \\ 61 & 61 & 61 \\ 51.83 & 37.78 & 11.94\end{array}$

Mean of dependent variable 51.83 37.78

\begin{tabular}{ccc}
1048 & 530 & 529 \\
530 & 530 & 529 \\
61 & 61 & 61 \\
52.96 & 40.53 & 9.26 \\
\hline
\end{tabular}

530

530

61

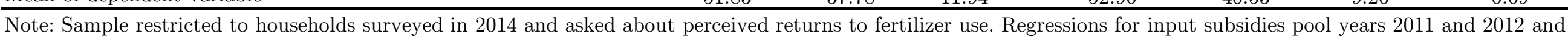
control for the year. 2011 input allocation information comes from 2011 survey. 2012 input and food allocations information comes from 2012 survey. Omitted age category is less than 26. Standard errors clustered at the village level. All regressions control for village fixed effects.

* significant at $10 \%$;* significant at $5 \%$;** significant at $1 \%$ 
Table A10. Perceived Within-Village Heterogeneity among Village Chiefs

Can you easily categorize households in the village with land better suited for fertilizer and those with land not so well suited for fertilizer?

Yes

Can you easily categorize households in the village in two groups, those who are very poor and those who are less poor? Yes

Do you know which families in the village are having specific difficulty with money at a given time?

I know how everyone is doing

I know how some people are doing

I do not know

Do you know who is likely to have money to buy fertilizer for the coming planting season and who will not?

I know how everyone is doing

I know how some people are doing

I do not know

Number of observations

Notes: From survey of village chiefs conducted in 2014. See text for details. 


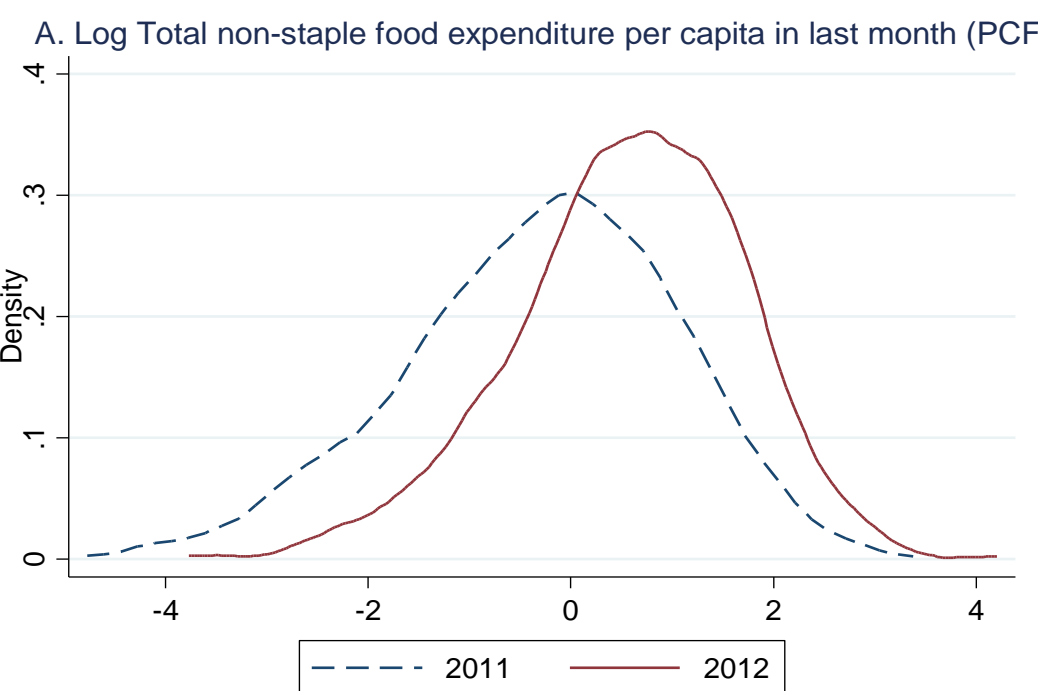

(2012): Within-village SD=1.09, Between-village SD $=.27$

B. Log gain in farm production from fertilizer use (winsorized top 5\%)

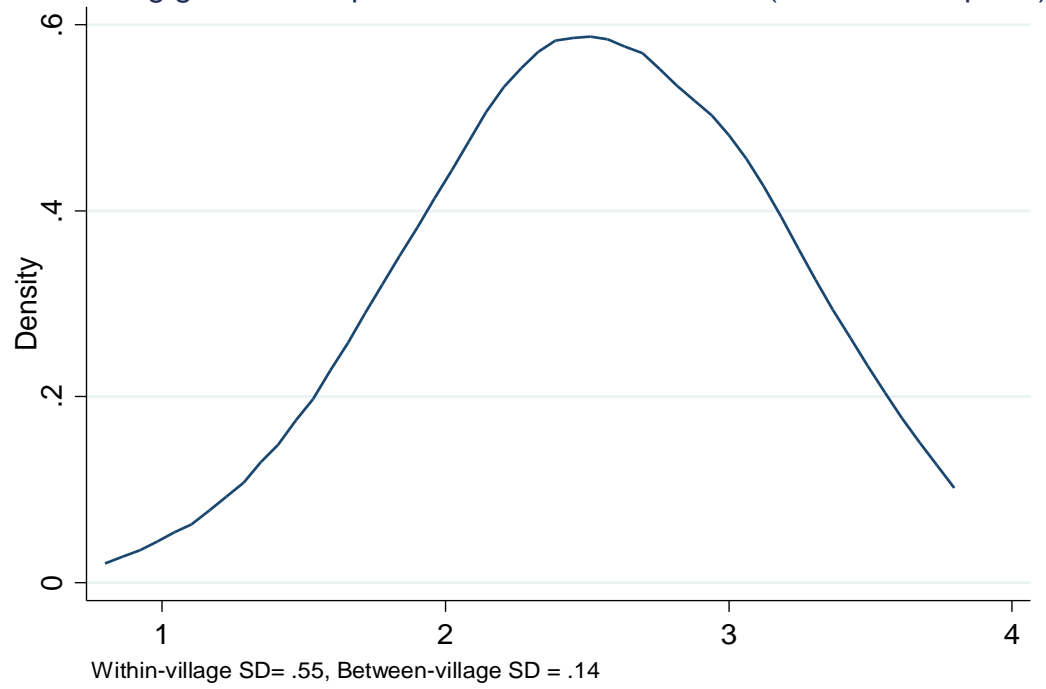

C. Variation in PCF within Fertilizer Returns Level

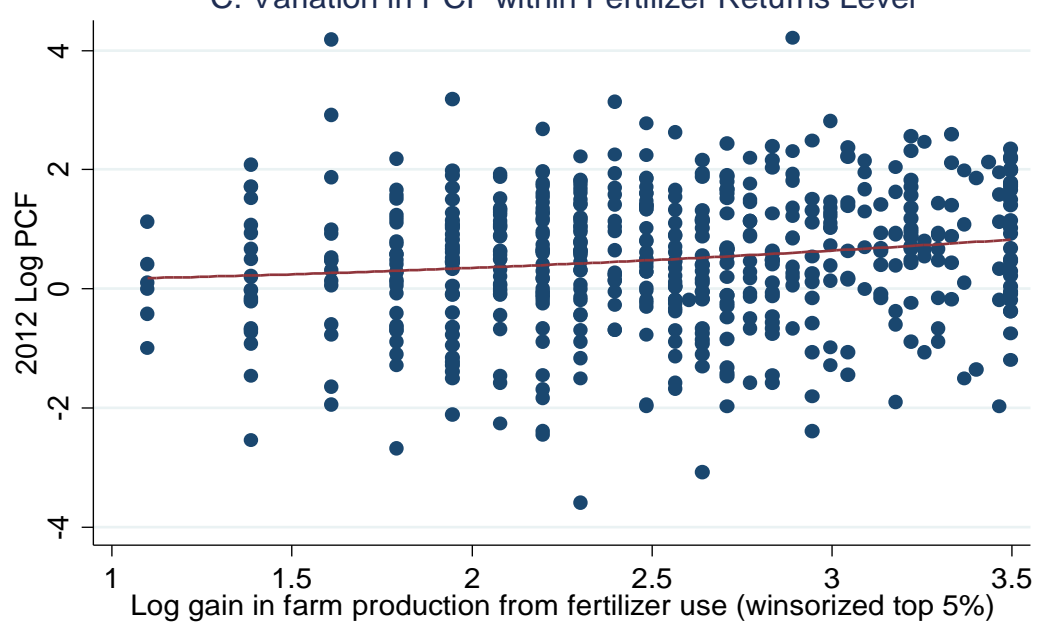

Quadratic fit

Notes: Gain in farm production expressed in $50 \mathrm{Kg}$ bag units. 


\section{Input Subsidy}
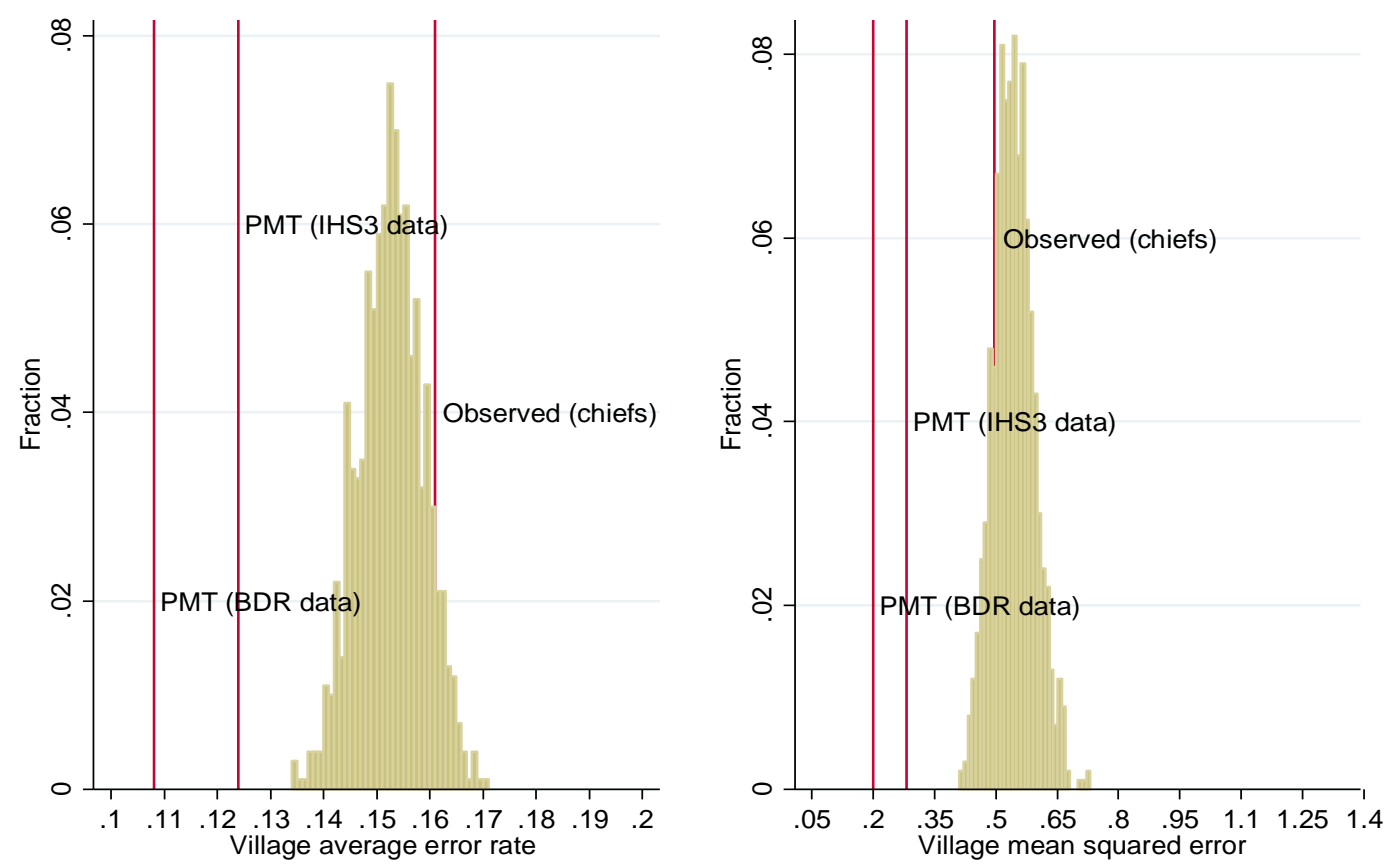

\section{Input Subsidy}
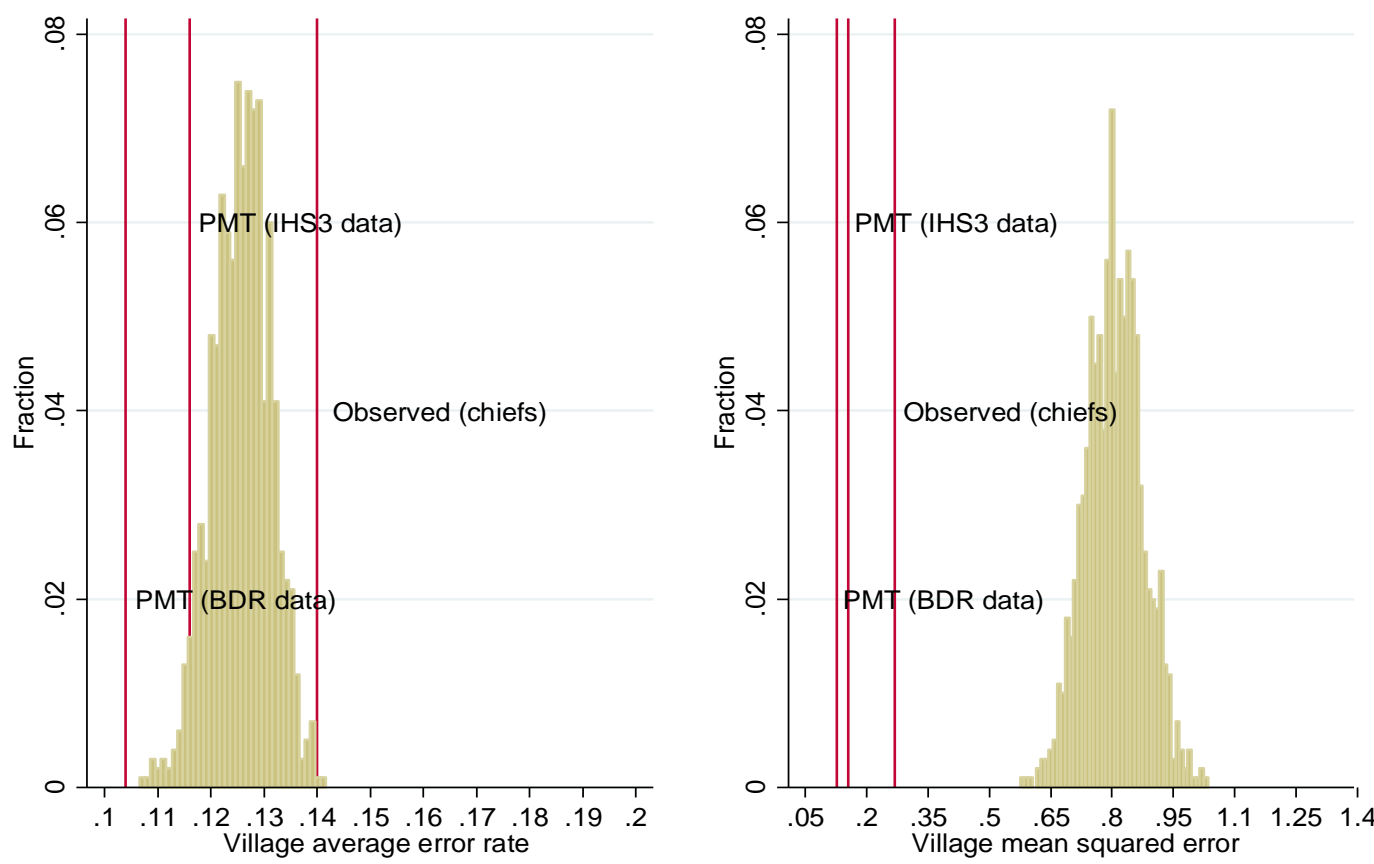

\section{Food Subsidy}
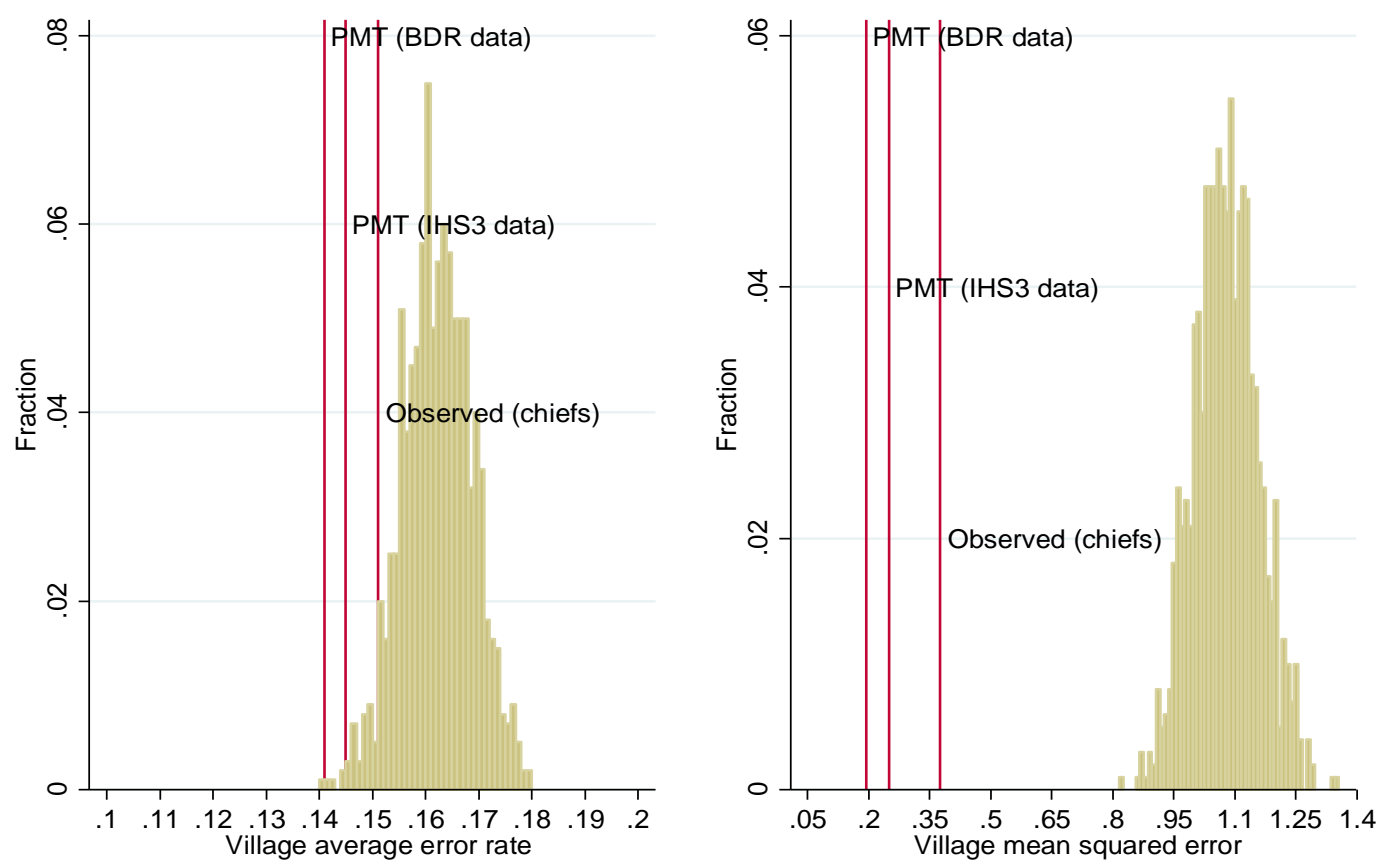
Figure A3. Comparing chiefs' allocation to counterfactual allocations
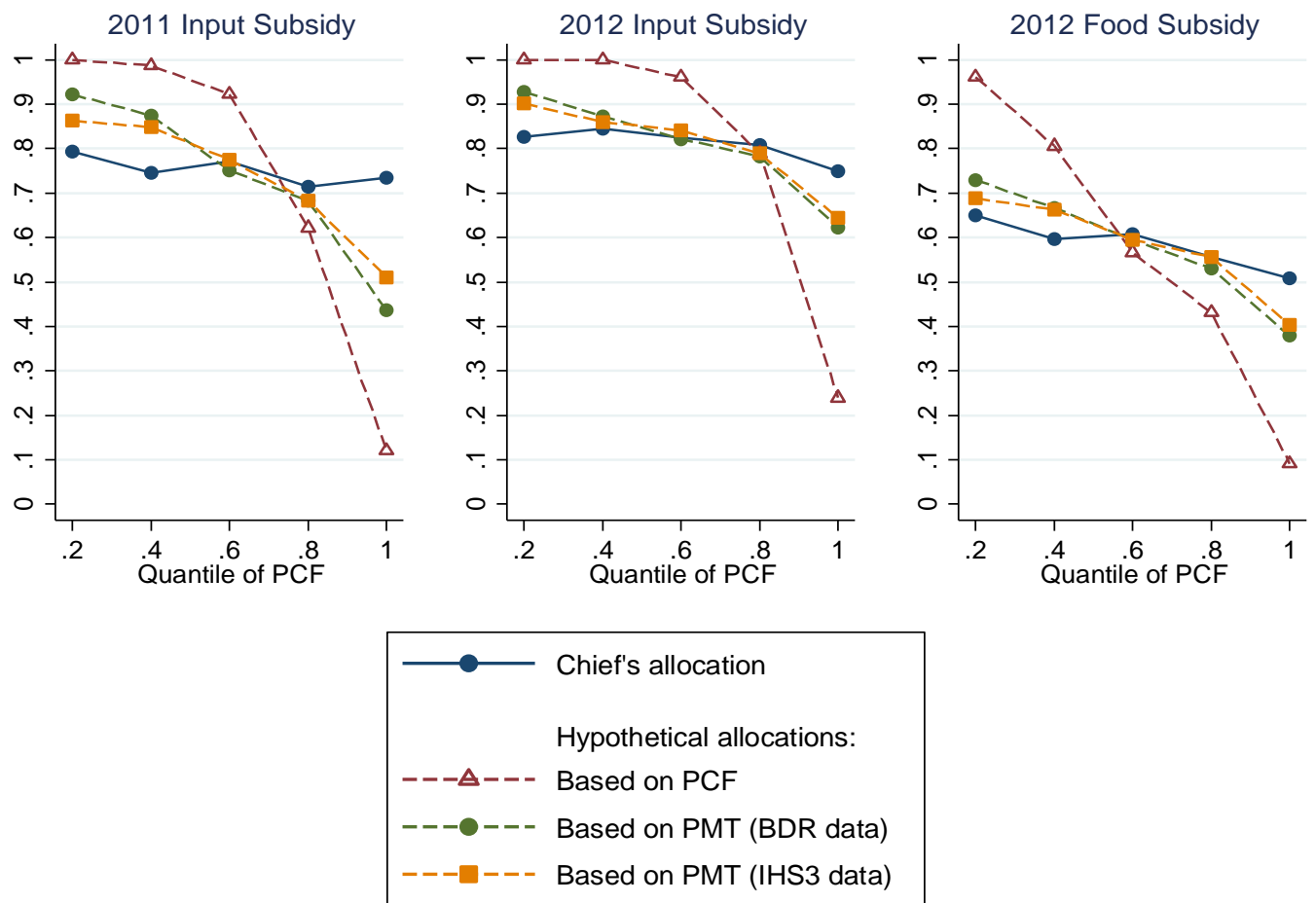

Notes: See main text section 4.2 and figure 1 notes.

IHS3 = Malawi Third Integrated Household Survey, a representative survey conducted by Malawi's National Statistical Office from March 2010 to March 2011.

Figure A4. Model simulation: Optimal Allocation with Productive Efficiency Consideration

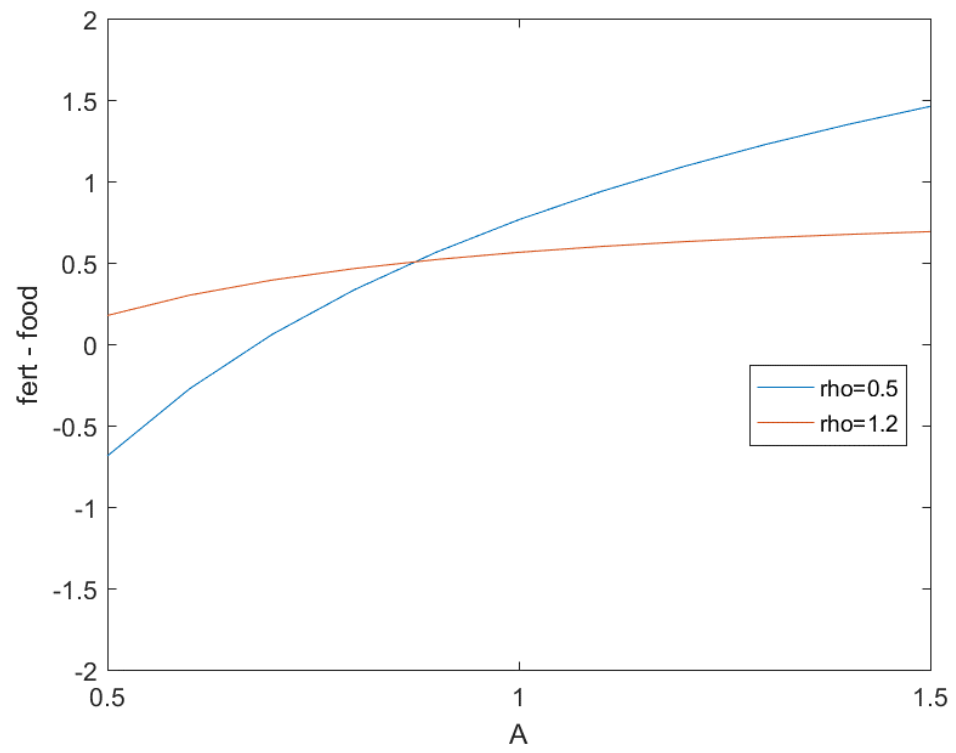

Notes: see text section 5 . 